\title{
Information Visualization for Selection in Design by Shopping
}

\author{
Audrey Abi Akle \\ ESTIA, 64210 Bidart, France \\ Laboratoire Genie Industriel, CentraleSupélec, Université Paris-Saclay, 92290 Châtenay-Malabry, France \\ e-mail : a.abiakle@estia.fr
}

Stéphanie Minel

ESTIA, 64210 Bidart, France

\section{Bernard Yannou}

Laboratoire Genie Industriel, CentraleSupélec, Université Paris-Saclay, 92290 Châtenay-Malabry, France

\begin{abstract}
In Design by Shopping, designers explore the design space to gain an insight into trades and feasible and impractical solutions, as well as to learn about alternatives before optimization and selection. The design space consists of multidimensional sets of data and, in order to select the best design from amongst numerous alternatives, designers may use several different graphs. In this study, we test to find the most appropriate graph to indicate the best solution corresponding to a set of objectives represented by a design scenario (1). A further constraint is that this must be done in the shortest possible time (2). Three graph types are tested in three different design scenarios where one car has to be chosen from a total of 40. A response quality index is proposed which computes the quality of a designer's choice for any given scenario. In total, 90 tests with 30 participants were performed. The Parallel Coordinates Plot proved to be the best graph for selection in Design by Shopping.
\end{abstract}

Keywords. Visual Design, Computer Aided Design (CAD), Decision Making

\section{Introduction}

In engineering design, once the design has been formalized, a necessary design task is to select from amongst candidate designs or parametric values (Otto \& Antonsson, 1993). This can be done in the preliminary concept phase, where the designer has to choose one solution over other alternatives, or in the detail design, where the designer has to choose particular values to use in a design model. The main challenge when designing complex systems (such as cars or aircraft) lies in resolving the inherent trade-offs that exist between the overall system and subsystems, and between conflicting and competing objectives.

When exploring the design space, the design is selected after evaluating the elements present in order to identify optimal solutions by reducing the design space to an area of performance. In this method, visualization techniques are used as decision support tools. Graphs are useful to quickly visualize feasible solutions as opposed to impractical solutions, as well as those violating engineering constraints or client requirements. Three different situations can be represented with more or less data:

- Representing the single vector of design parameters featuring the product solution, $(X)$ : this refers to the feasible design space,

- Representing the single vector of solution performances for feasible solutions, $(Y)$ : this refers to the feasible performance space,

- Representing two sets of design parameters and corresponding performances for feasible solutions (respecting constraints and requirements), $\left(\begin{array}{l}X \\ Y\end{array}\right)$ : this refers to the feasible design and performance space.

Graphical supports are effective for design parameters (Simpson et al., 2007), engineering optimization (Barron et al., 2004) and conceptual design (Yannou et al., 2005). There is already much research in visual design and it has been shown that fast graphical design interfaces impact user performance in terms of design efficiency, 
design effectiveness and the design search process (Ligetti et al., 2003). Various tools for exploring the design space with different graphs exist, namely: the ARL Trade Space Visualizer (Stump et al., 2004), the VIDEO tool (Kollat \& Reed, 2007), the LIVE tool (Yan et al., 2011, 2012) and the Rave tool (Daskilewicz \& German, 2012).

In fact, these graphs are useful for representing multidimensional sets of data with unlimited numbers of alternatives (design points). Exploring the design space consists of three main phases: discovery, narrowing and selection. During the selection phase, designers face a reduced design space with a limited number of design points (in a performance area). The following figure (Fig 1) shows which graphs best help designers in selecting an optimal solution during the final phase of the design process.

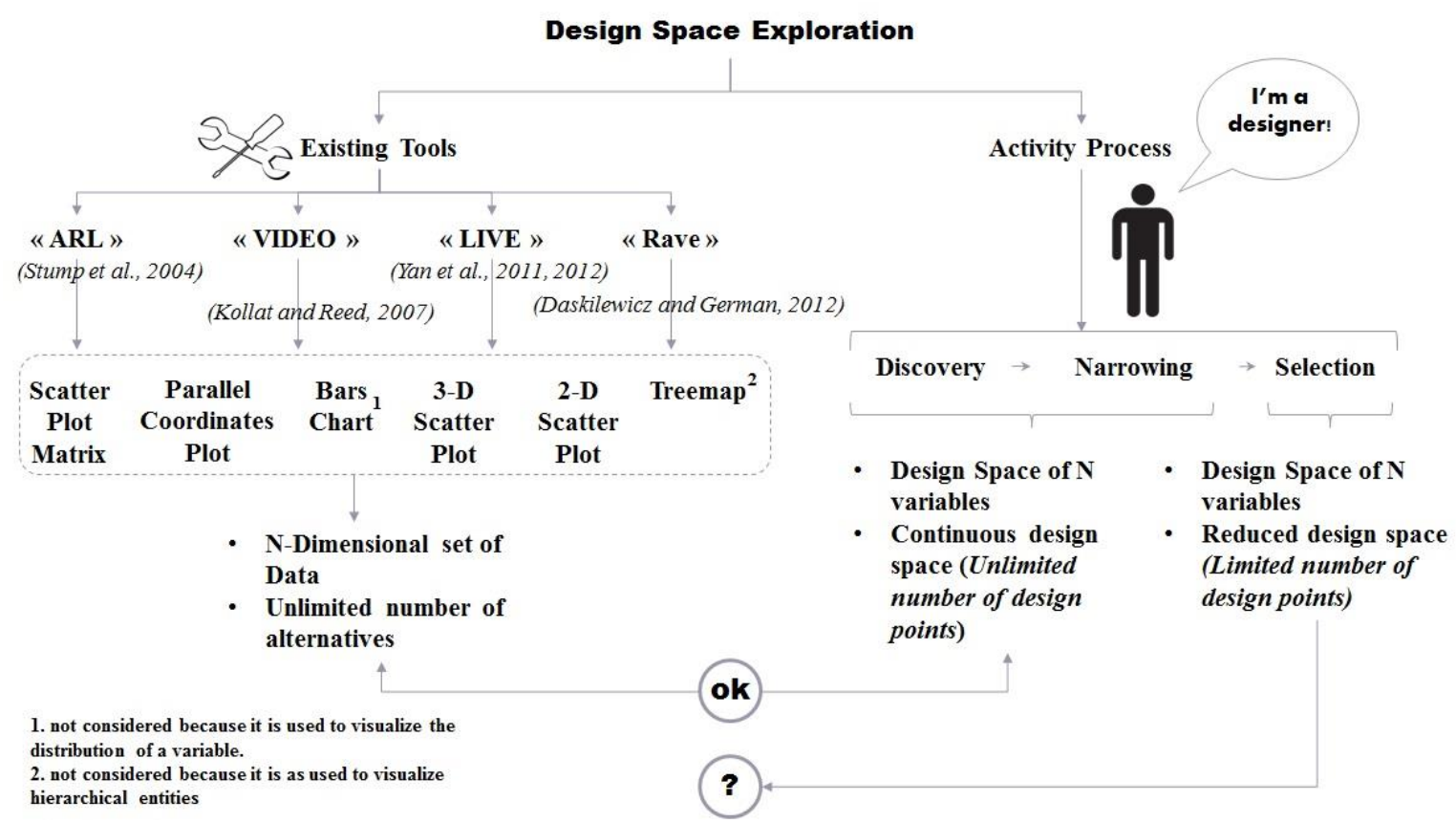

Fig 1. From exploring the Design Space to the research question

We know that exploring the design space is the embodiment of a paradigm where designers shop for the best solution. It is called Design by Shopping, a term coined by Balling (1999). Indeed, Balling (1999) noted that the traditional optimization-based design process to "formulate the design problem, obtain analysis models and execute an optimization algorithm" leaves designers unsatisfied. Designers, like consumers, want to "shop" to gain an insight into trades, feasible and impractical solutions, and to learn about their alternatives before making decisions. Design by Shopping firstly allows designers to explore the design space and secondly to optimize and choose an optimal solution from a set of possible designs, and then develop realistic expectations with regard to what is possible.

So, in Design by Shopping, the selection phase should be supported by graphs that allow designers to observe all the design alternatives, therefore enabling them to distinguish between right and wrong responses. The graph should allow differentiation between design parameters and performance variables. With graphs, the designer needs to compare candidates according to criteria. In this way, the graph should help the designer find a so-called "optimal" solution. In this sense, it should not create confusion or increase the designer's workload.

We have thus identified three graphs which are useful for representing multidimensional sets of data ( $>3$ variables) and with a limited number of alternatives (<50): Combined Table $(C T)$, Parallel Coordinate Plot (PCP) and Radar Chart (RC). We carried out experiments with 30 participants and designed three scenarios to mimic the design activity. The framework was simplified in order to focus our study on the selection phase (13 design parameters and 5 performance variables where it is necessary to achieve trade-offs between conflicting objectives). We identified the graph best suited to the selection phase in Design by Shopping: the Parallel Coordinates Plot (PCP).

In this paper, we describe the different approaches to design selection in the first section, followed by a description of the tools available for exploring the design space. We then characterize the Design by Shopping paradigm and efficient graphs for the selection phase, before presenting the experimental design and the measurements used in the experiment that lead to our study's results. Finally, we discuss the results and conclude.

\section{Selection In Design approaches}


As already noted by Yannou et al. (2013), design optimization is a well-established field of research with two primary approaches: unique objective function optimization and multiple objective optimizations. In our case, we are concerned with the second approach in which design solutions are computed and/or a desired compromise (on the Pareto surface for instance) is found either automatically or interactively.

In the "automatic" approach, a finite set of "best" solutions is directly proposed to the designer. There are many methods, such as the weighted-sum of preferences, indifference points or compensation of the weight (see Scott \& Antonsson, 2000, 2005). In this case, we also consider the "semi-automated" approach where the direct specification of importance weights is an ad-hoc process, for instance. This approach involves the designer at the end of the process.

In the "interactive" approach we distinguish two close paradigms: Uncertainty Reduction and Design by Shopping. In the Uncertainty Reduction paradigm, the designer iteratively reduces intervals on variables allowing design knowledge to be gained, thereby reducing uncertainty through the process of convergence towards an optimal solution (Malak et al., 2009). It is worth mentioning the use of Constraint Programming as a relevant method for reducing uncertainty in the preliminary design stage (cf. Yannou \& Hamdi, 2004; Yannou et al., 2009). With this paradigm, the designer is part of the process and the design selection is derived from the process. In the Design by Shopping paradigm, the designer explores feasible design solutions and interactions between variables. A design point can be selected and consequently the design space is reduced by discovering knowledge and gaining insights during the process (Zhang et al., 2012). With this paradigm, the designers are part of the process and they are direct in the simulation loop.

We also focus on the work of Miller et al. which attempts to capture the key attributes from the decision-making literature tailored to the engineering domain (Miller et al., 2013). More precisely, they compare three models: the widely known normative decision-making model, the marketing model of Shocker et al. (1991), and the trade space exploration model developed by Simpson et al. (2008).

The first one concerns the traditional optimization process that is to develop a model, defines constraints/objectives, chooses an algorithm, optimizes and checks satisfaction (see Miller et al. (2013)). This process (and by extension, selection using this process) follows the "automatic" approach already mentioned. The second model comes from the domain of marketing and was defined by Shocker et al. (1991) where "consumers" sequentially reduce the space of considered choices through a number of discrete sets. There are four sets: the universal set corresponding to all possible choices, the awareness set corresponding to solutions for which the decision-maker becomes aware, the consideration set corresponding to the potential solutions and the choice set defined as the final consideration set prior to a final choice. Finally, the last model described by Miller et al. (2013) is the Trade Space Exploration which is an embodiment of the Design by Shopping paradigm. The authors point out that this model combines the first two; it describes the "arrows" between sets defined in the marketing model. Indeed, the visualization tools are used to assist Decision-Makers in constructing their preferences while the space is proceeded upon to reduce the universal sets into a sequence of consideration sets to a choice set and finally a choice.

Design by Shopping was coined by Balling (1999). He noted that the traditional optimization-based design process of "formulate the design problem, obtain analysis models and execute an optimization algorithm" leaves designers unsatisfied with their results because the problem is usually improperly formulated: "the objectives and constraints used in optimization were not what the owners and stakeholders really wanted. In many cases, people do not know what they really want until they see some designs" (Zhang et al., 2009). Design by Shopping places emphasis on revealing the range of options available without presuming that all the selection criteria have previously been elicited (Feather et al., 2008).

Designers, like consumers, want to "shop" to gain an insight into trades, feasible and impractical solutions, and to learn about their alternatives before making decisions. Design by Shopping initially allows designers to explore the design space, before choosing an optimal solution from a set of possible designs and finally developing realistic expectations of what is possible. 
According to Ferringer et al. (2009), "the ultimate reduction of the solution space to a single Decision-Maker preferred design proceeds using this trade-off information in a Design by Shopping paradigm". Rothrock \& Narayanan (2011) noted similar findings reported in other fields. For example, Wilson \& Schooler (1991) showed that people do worse at some decision tasks when asked to analyze the reasons for their preferences or evaluate all the attributes of their choices. Shanteau (1992) observed that when people are dissatisfied with the results of a rational decision-making process, they often change their rating to achieve their desired results. This paradigm introduces greater "control" for decision-makers by "allowing them to first form their preference based on the visualization of the entire design space, and then choose an optimal design." (Rangavajhala, 2007). This paradigm is as much about eliminating the wrong answers as it is about finding the right answer. Design by Shopping is classified as an a posteriori articulation of preferences used to solve multi-objective optimization problems. It replaces Human directly in the simulation loop.

In Design by Shopping, therefore, the selection phase should be supported by graphs that allow designers to observe all the design alternatives, as well as the wrong and right responses. The graph should allow differentiation between design parameters and performance variables. The designer should be able to compare candidates according to specific criteria. The graph should be a help to the designer, a means to select the socalled "optimal" solution. In this sense, it should not create confusion or an additional workload for the designer.

\section{Interactive design visualization}

It has already been shown that fast graphic design interfaces impact user performances in terms of design efficiency, design effectiveness and the design search process (Ligetti et al., 2003). The use of interactive design visualization is not new in engineering design field, and a number of articles deal with this topic. Winer and Bloebaum propose Visual Design Steering (Winer \& Bloebaum, 2001) which enables the use of visualization as a support tool in the analysis and optimization phases of a design process. Other works focus on overpassing 2D and 3D representations and limitations with multidimensional optimization problems: Cloud Visualization (Eddy \& Lewis, 2002), BrickViz (Kanukolanu et al., 2006), Hyper-Radial Visualization (Naim et al., 2008), SelfOrganization Maps (Nekolny et al., 2010) and continuous visualization as RAVE tool (Daskilewicz \& German, 2009; 2012). Some have focused on the visualization optimal solution as n-Dimensional Pareto front (Agrawal $e t$ al., 2004). In our study, since we are concerned by selection, we are interested in graphs that represent design points. There are existing tools for exploring design points and the design space using different graphs, namely: the ARL Trade Space Visualizer (Stump et al., 2004), the VIDEO tool (Kollat \& Reed, 2007), the LIVE tool (Yan et al., 2011, 2012) and the Rave tool (Daskilewicz \& German, 2012).

The ARL Trade Space Visualizer (Stump et al., 2004) is used to visualize both design parameters and performance variables with Scatter Plot Matrix, Parallel Coordinates Plot and Bar Charts (Fig 2). 
Abi Akle A., Minel S., Yannou B. (2016) 'Information Visualization For Selection In Design By Shopping', Research in Engineering Design, 28(I), pp. 99-117, dai: 10.1007/s00163-016-0235-2

a)

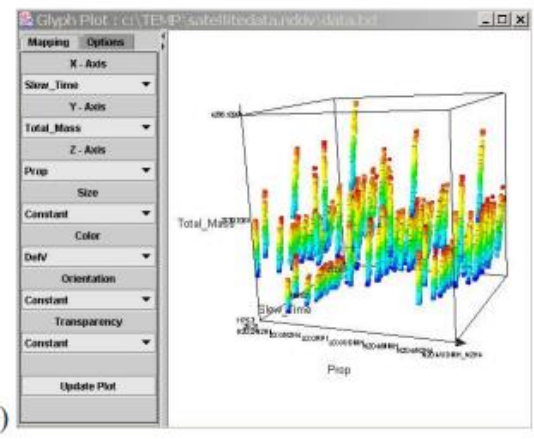

b)
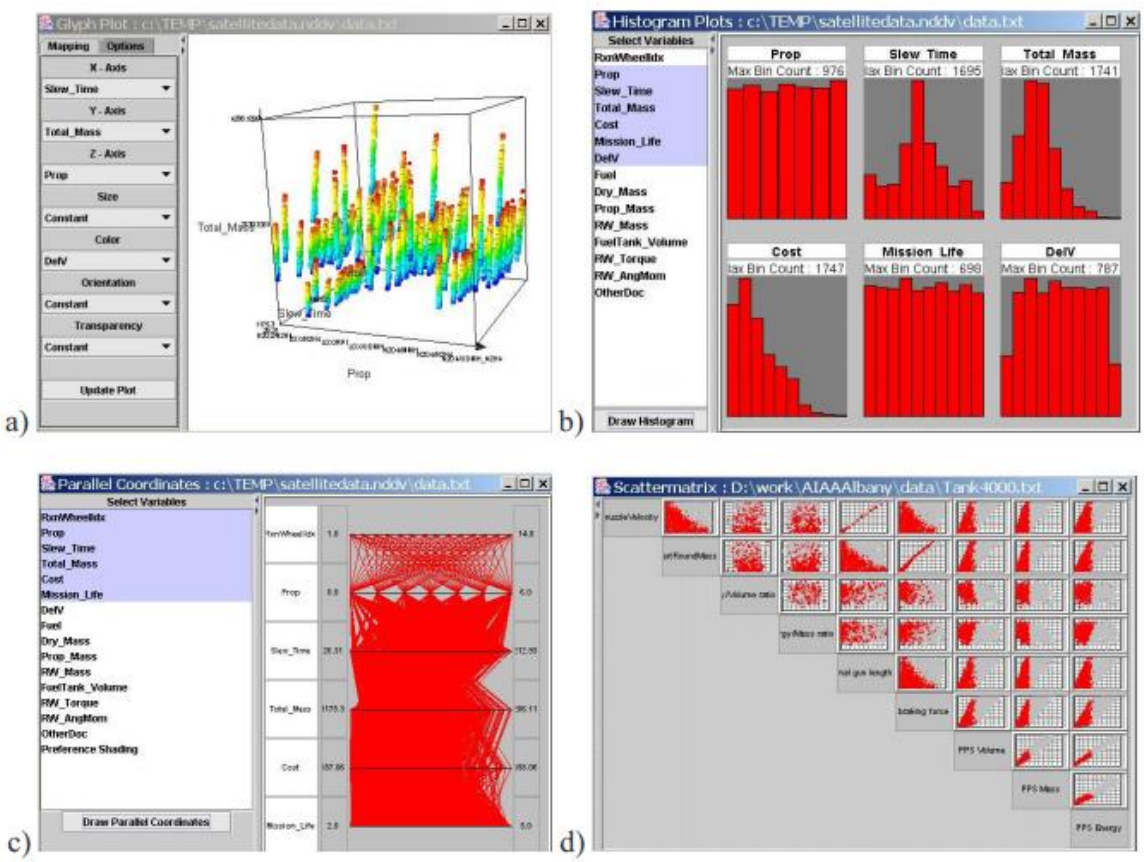

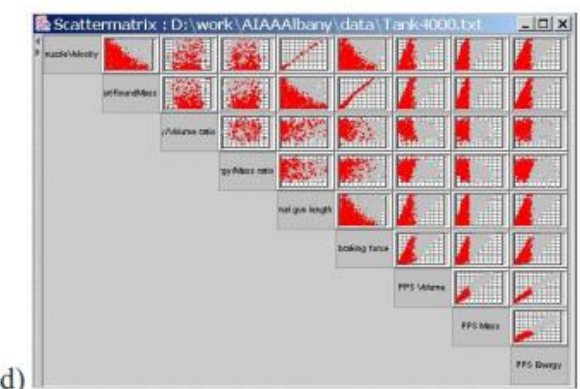

Fig 2. Screenshot of ARL Trade Space Visualizer: a) Glyph Plot, b) Parallel Coordinates, d) Scatter Matrix (Stump et al., 2004)

The VIDEO tool (Kollat \& Reed, 2007) is used to separately visualize on two graphs the objective space (ie. performance variables) and decision space (ie. design parameters) with the 3-D Scatter Plot using color and size glyphs (Fig 3).

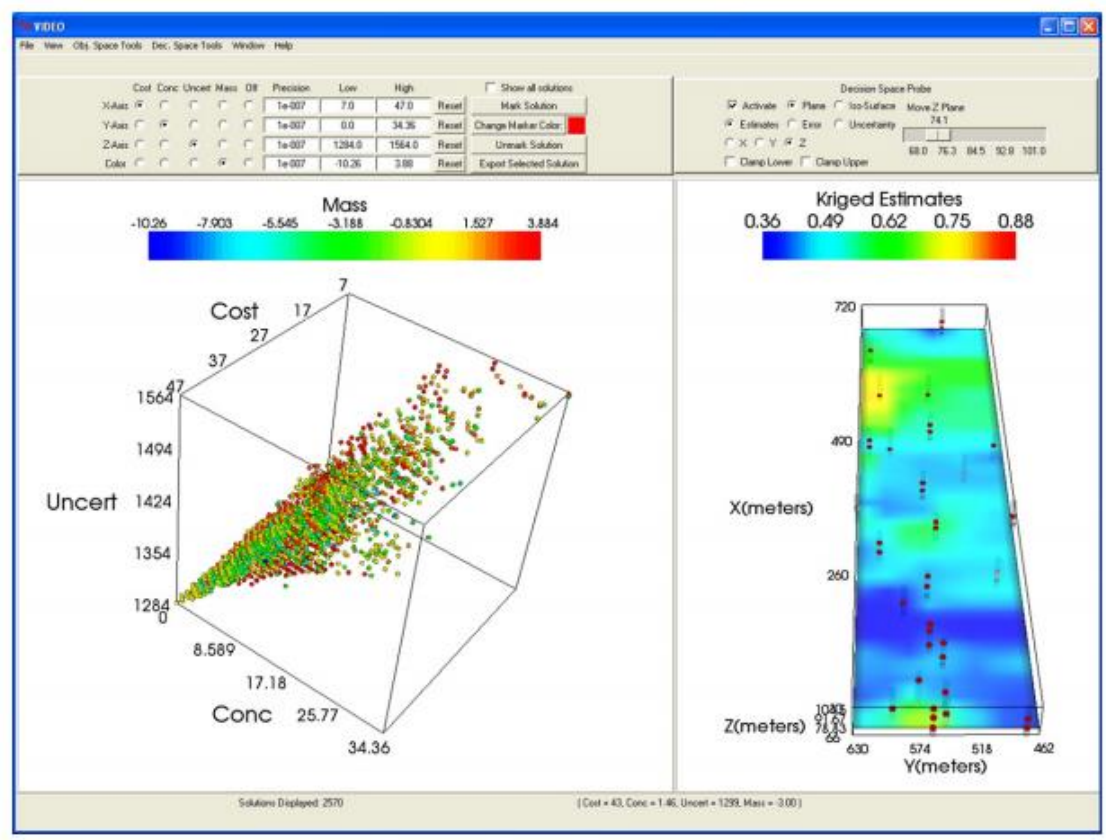

Fig 3. Screenshot of VIDEO system (Kollat \& Reed, 2007)

The LIVE tool (Yan et al., 2011, 2012) is, on the one hand, used to visualize in two graphs, the input variables (design parameters) on one side (Fig 4 b.) and the output variables (performance variables) on the other (Fig 4 a.). On the other hand, a tree structure is displayed which represents the classification of input variable combinations (Fig 4 d.). Both spaces (input/output) are projected in a 2D Scatter Plot in which color and shape glyphs (cluster creation) can be added. The tree structure is presented in a Treemap (Shneiderman, 1992) in which each node corresponds to an input attribute with a splitting value. Each leaf of the tree specifies the 
Abi Akle A., Minel S., Yannau B. (2016) 'Infarmation Visualization For Selection In Design By Shopping', Research in Engineering Design, 28(I), pp. 99-117, dai: 10.1007/s00163-016-0235-2

expected output value (with color scale), as a consequence of the particular input values described by the path from the root to that leaf (Fig 4).

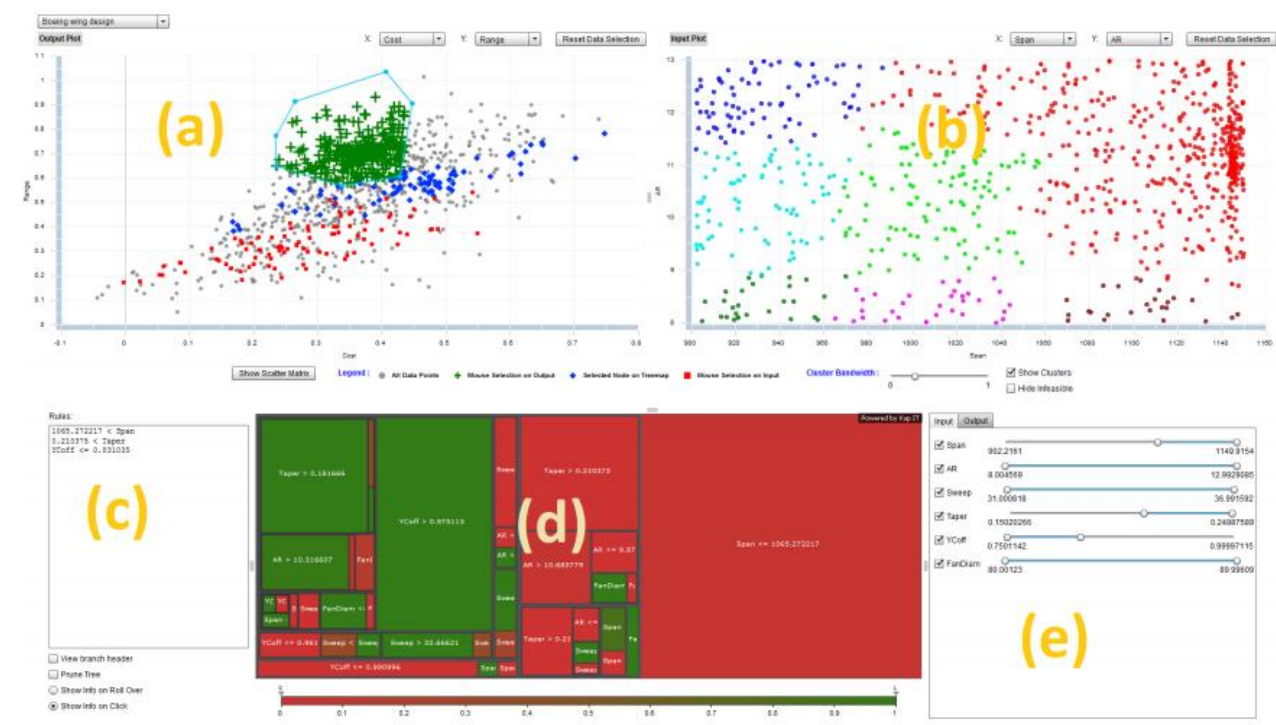

Fig 4. Screenshot of live system: (a) scatter plot of performance output variables; (b) scatter plot of design input variables (showing clustering results); (c) text representation of decision rules; (d) treemap visualization of decision tree; (e) adjustable sliders for ranges of input and output variables (Yan et al., 2011, 2012)

The Rave tool (Daskilewicz \& German, 2012) is a computational framework designed specifically as a research platform for design decision-support methods. It provides a "blank canvas" on which we can arrange graphs, tables, images, text, and user interface controls (automatically linked together). In order to visualize design points, this tool proposes several graphs as line plot, scatter plot, 3D scatter plot, scatter plot matrix, parallel coordinates plot, bar charts and density scatter plot (Fig. 5). Rave also provides continuous visualization.

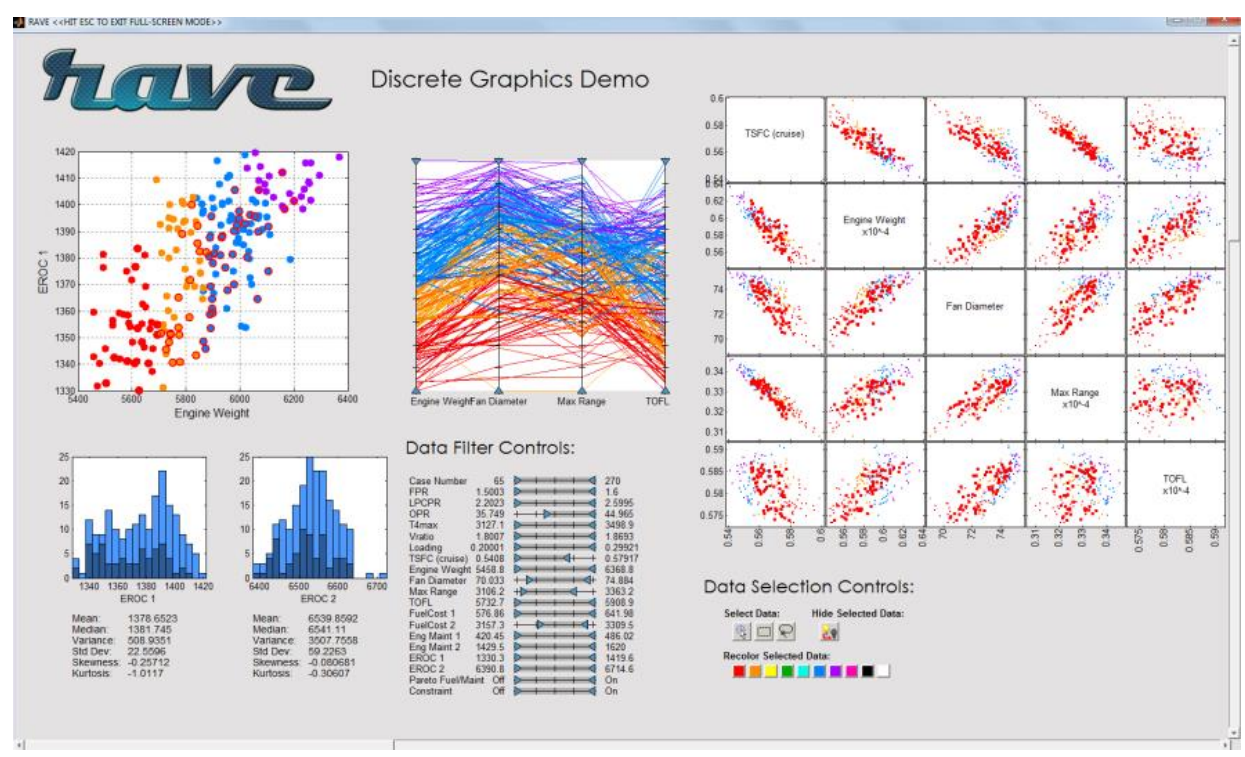

Fig 5. Screenshot of Rave tool (Daskilewicz \& German, 2012)

These graphs are useful for representing multidimensional sets of data with an unlimited number of alternatives (design points). Clearly, these graphs are adapted to this method especially when a designer generates a sample of design points, but the design space exploration activity consists of three phases: discovery, narrowing and selection; and during the selection phase, designers face a reduced design space with a limited number of design points (compared to the first two phases). As already noted, exploring the design space is the embodiment of a 
Abi Akle A., Minel S., Yannou B. (2016) 'Information Visualization For Selection In Design By Shopping', Research in Engineering Design, 28(I), pp. 99-117, dai: 10.1007/s00163-016-0235-2

paradigm where designers shop for the best solution. In this context, it should identify the specific characteristics of this paradigm especially for the selection phase.

\section{Graphs For The Selection Phase}

In our context of achieving trade-offs and selecting an optimal solution, several graphs (design space representations) are available to us. As already mentioned, this is a case-representation of multidimensional sets of data with limited numbers of alternatives (design points). Based on the works of Miettinen (2014) and Keim (2000) (amongst others) about graph characteristics, we identify the values table, the table with heatmap, the combined values-heatmap table, radar chart and parallel coordinate plot (PCP). Gettinger et al. (2013) have already compared the values table, the heatmap and the PCP for multicriteria decisions and they conclude that it is necessary to check the efficiency of the combined values heatmap table. Also, these authors do not consider the radar chart in their work. Thus, we propose comparing the following three graphs to select an optimal solution (design decision) in design space exploration: the Combined Table (CT), the Parallel Coordinates Plot (PCP) and the Radar Chart (RC). The interactive graphs are available at the following address:

http://these.aaa.alwaysdata.net/expe1/

\subsection{Combined Table (CT)}

The Combined Table is a combination of table values and a table with a heatmap (Fig 6). In our implementation, each row is a design point (or alternative) and each column is a variable (or component). The interaction with the graph takes place on the labels at the top of each column. By clicking on these labels, the values in the columns are sorted from highest to lowest. In addition to the values in the table, we added a heatmap. Theoretically, heatmaps are matrices in which the cells are colored according to their values. We have already shown in (Abi Akle et al., 2013) that the most efficient visualization for a decision-maker would be a monochromatic heatmap in red. In each column, the highest value has a bright red cell. The colors used range from red for the column's highest value to white for the lowest. In addition, on mouse over, the entire row of values (corresponding to an alternative or possible solution) is underlined and the alternative's title appears at the top left of the interface. This representation is particularly useful for identifying patterns such as correlations (Cook et al., 2007).

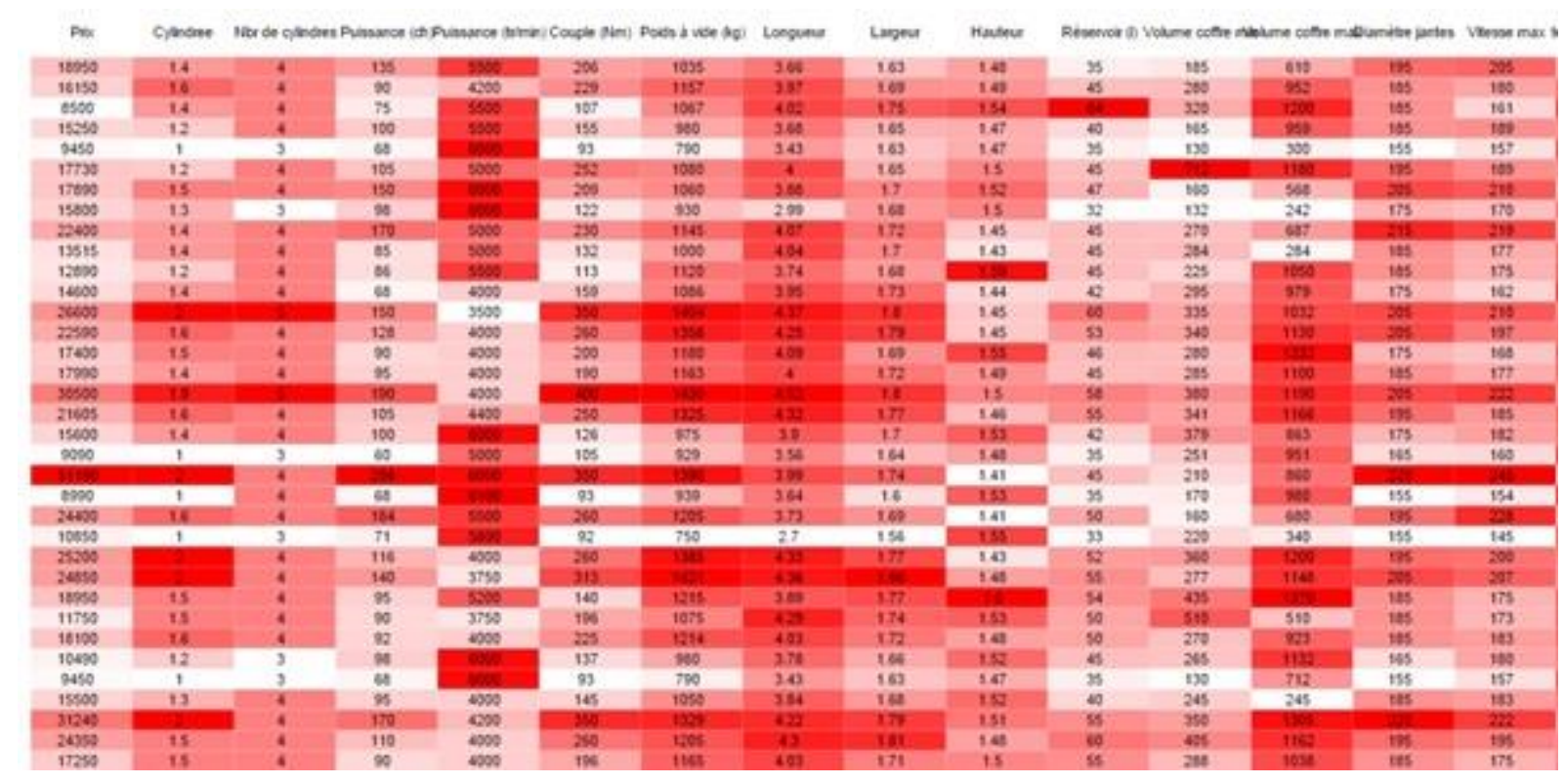

Fig 6. Screenshots of Combined Table

\subsection{Parallel Coordinates Plot (PCP)}

The Parallel Coordinates Plot is defined as a graph displaying multiple criteria without drastically increasing the complexity of the display (Inselberg, 2009). In PCP, variable values are displayed on separate axes laid out in 
Abi Akle A., Minel S., Yannau B. (2016) 'Infarmation Visualization For Selection In Design By Shopping', Research in Engineering Design, 28(I), pp. 99-117, doi: 10.1007/s00163-016-0235-2

parallel. The design points (or alternatives) are depicted as profile lines that connect points on the respective axes. According to Gettinger et al. (2013), this representation can be readily interpreted and provides a good overview. Furthermore, patterns such as positive, negative and non-trivial (multiple) correlations may be identified at a glance. In our implementation, the interaction is directly applied on the graph. To filter the values, simply place the mouse on one of the axes and, with a click, drag the cursor to obtain a desired range of the criteria like a window, outside which value vectors are excluded. In addition, the mouse, when moved above a line, is used to display the title of the design point (or alternative) at the top left of the interface (Fig 7).

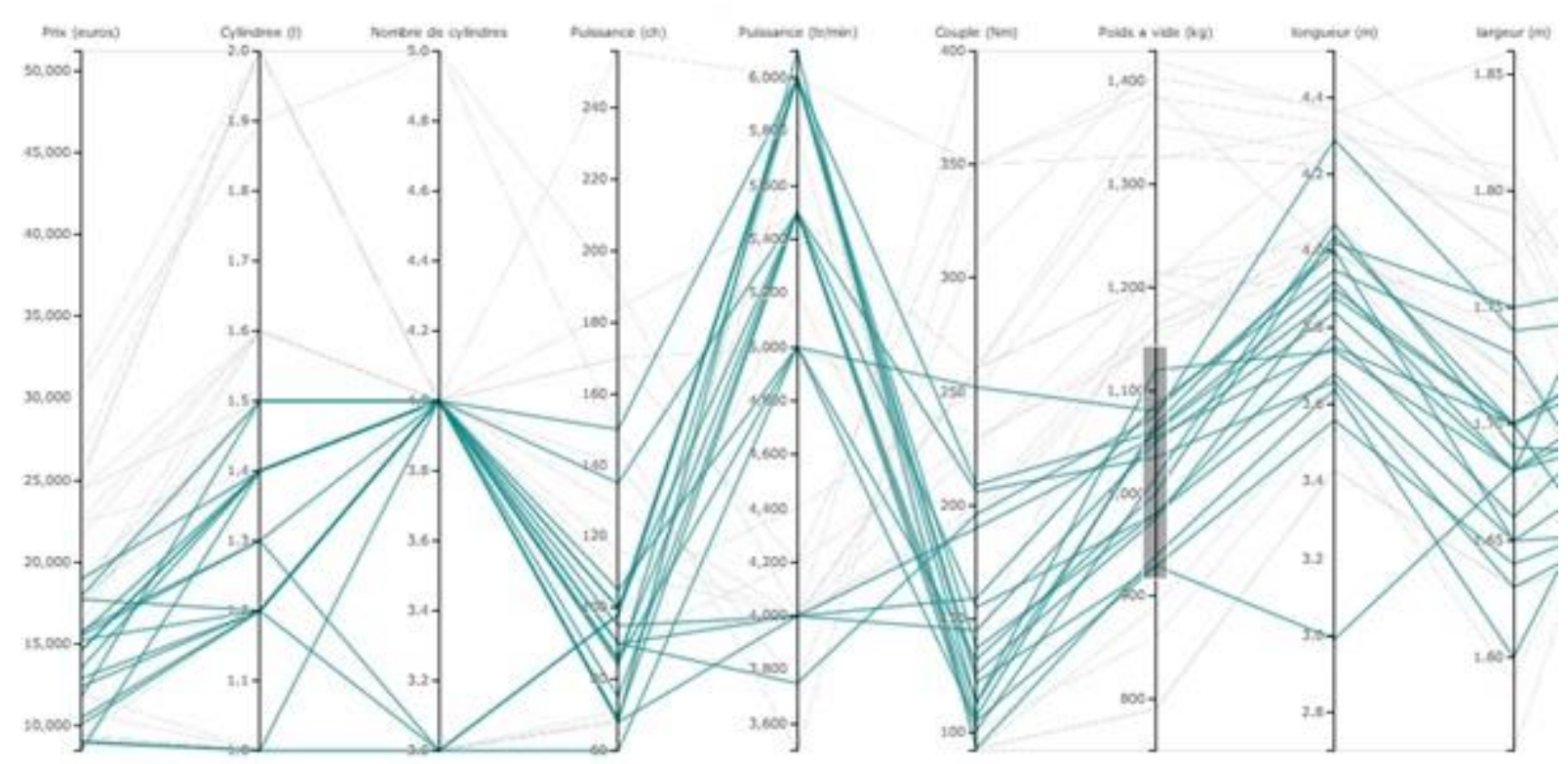

Fig 7. Screenshots of Parallel Coordinates Plot

\subsection{Radar Chart (RC)}

In a Radar Chart, variable values are displayed on separate axes laid out in a concurrent radial manner (Fig 8). As with PCP, the design points are depicted as profile lines that connect points on the respective axes. In our implementation, interactions are achieved by the mouse first on the points (on the axes) displaying the variable value and second on lines displaying the title of the design point (alternative). Filtering is done using a form. We chose to use a form so as to not overload the graph. In the field of health care (Saary, 2008), radar charts are seen as a form of powerful graph to effectively convey meaning of multivariate data. 


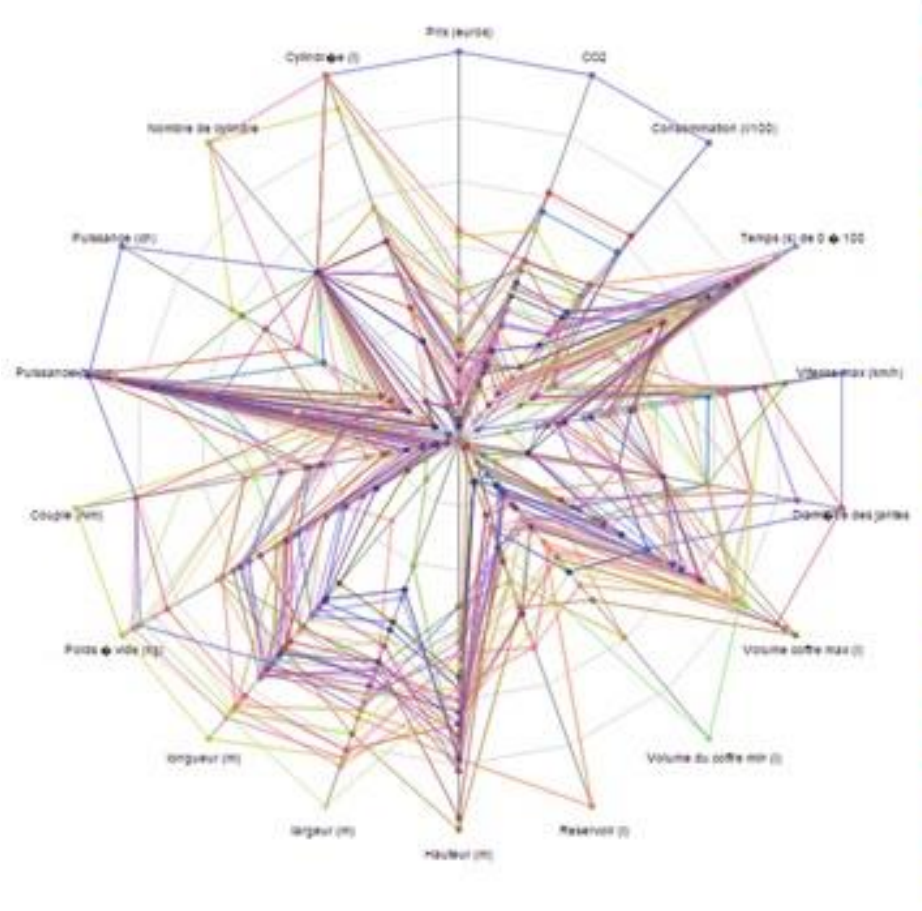

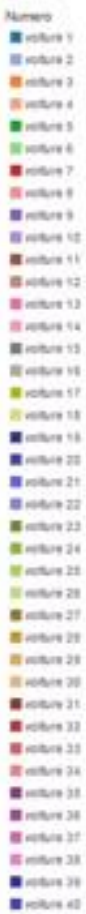

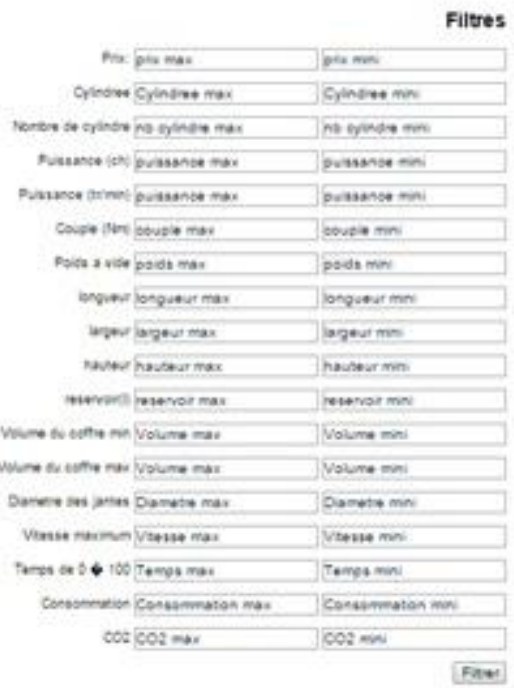

Fig 8. Screenshots of Radar Chart

\section{Experimental Design}

To answer our research questions, we conducted a controlled experiment that adopted a within-subject approach. Each participant performed the experiment on three graphs tested consecutively. To diversify the participant selection process, we proposed an experiment based on three scenarios leading to the selection of one alternative where a car has to be chosen. The three scenarios have been imagined to mimic the design activity in a simplified framework in order to focus on the selection phase of the design process. Scenarios are designed with personas method (see for example (Long, 2009)) as brief marketing in which a profile target is described. For each of the three scenarios, trade-offs between conflicting objectives have to be achieved in order to select an alternative, ie. choose an ideal in a car purchasing situation according to the scenario.

\subsection{The Three Scenarios}

We designed the Power Scenario, Size Scenario and Journey Scenario. The three scenarios are defined as follows:

- $\quad$ "Size" Scenario: The target user has a family of three children and a spouse. They work all day long in a big city where it is difficult to park. That is why you should select a car that is as small as possible in order to be able to park easily (width and length) but with sufficient internal volume for the target user and his/her family (height, trunk capacity and trunk (max-min) capacity)

- $\quad$ "Power" Scenario: Looking for the most powerful car. The maximum speed of the vehicle must be as high as possible with the greatest acceleration (time to accelerate from 0 to $100 \mathrm{~km} / \mathrm{h}$ ). The car should also have a high horsepower and significant motor torque. Finally, to ensure the car is as powerful as possible, you choose a car that is light (weight of the car).

- $\quad$ "Journey" Scenario: The target user is someone who travels almost every weekend with his/her car. You therefore look for a car with a big petrol tank and minimum consumption levels, because the target user doesn't want to stop often on the way to refuel, which would make the trip too expensive. Comfort is also an important factor: the car must be large (width and large trunk) and finally, a car with good handling should be selected (maximum rim diameter). 
The data used in each graphical representation is the same: 40 cars with 18 variables (13 design parameters and 5 performance variables) for each problem scenario (italic text in the scenario descriptions). The 18 variables are as follows: price, engine size, number of cylinders, horsepower, power (rpm), motor torque, car weight, width, length, height, tank, trunk (max. and min.) capacity, rim diameter, maximum speed, acceleration (time to reach $100 \mathrm{~km} / \mathrm{h}$ ), fuel consumption and $\mathrm{CO}^{2}$ emissions. The cars' names have been erased and replaced by a number (ranging from 1 to 40). Data is gathered from real cars. In order to obtain a wide range of data, we have chosen cars from different categories including large $4 \times 4$ and small city cars. In addition, all participants are aware that each criterion has the same weighting.

\subsection{Procedure}

The experiment is divided into three main steps (see Fig 9). The first step begins with a presentation of the experiment's objectives and a preliminary questionnaire in order to obtain subject profiles and their pre-existing knowledge of the graphs tested. The second step is the main part of our experiment and consists of testing the 3 graphical supports after a short training course. In this part, we ask the participant to read the scenario description, to "play" a role (as described in the scenario) and to use the graphic tool to deduce a single solution. We call the chosen solution a "trade-off" because the scenarios are designed with five conflicting objectives. It is therefore necessary to make a trade-off. The training course is about finding the needed item (car) as well as interacting with graphs. The third step is a questionnaire with the aim of collecting subjective measurements (participant effort, confidence, etc.).

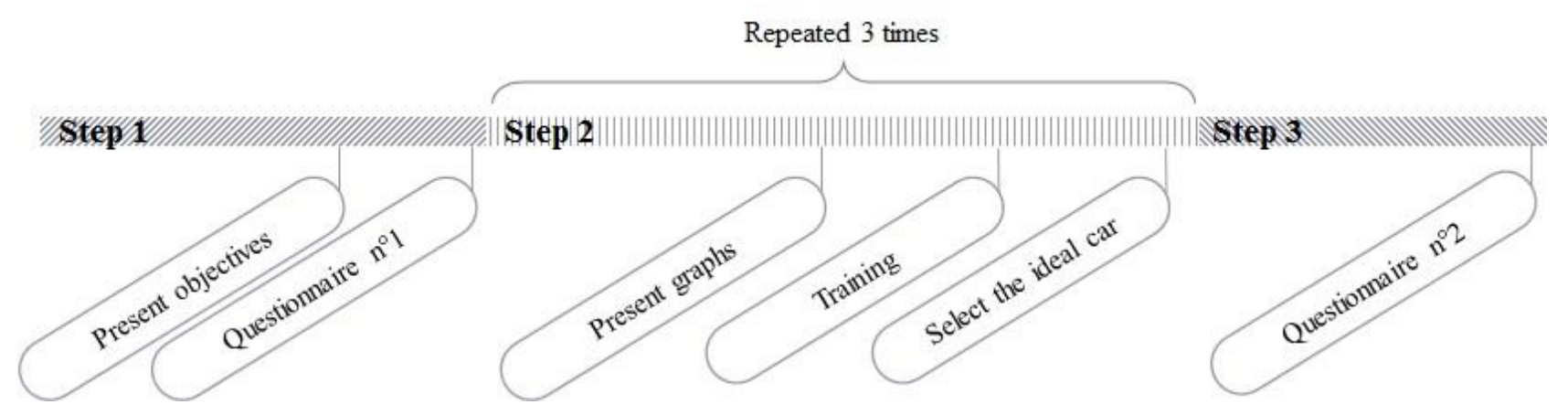

Fig 9. Illustration of the procedure

The total time for a complete session is about $1 \mathrm{~h} 10$ (ie. $35 \mathrm{~h}$ of experiments over 4 weeks). It is worth noting that for step 2, in order to avoid the effect of rank and order induced by the graph's sequence, we use the counterbalance method. In our case, this means different graphic sequences (eg. PCP - RC - CT, PCP - CT $\mathrm{RC}, \mathrm{CT}-\mathrm{PCP}-\mathrm{RC}$, etc.) and different scenario sequences. In addition, this method allows scenarios to be alternated for testing graphics and balancing the effect of participants' learning.

\subsection{Participants}

Subjects were recruited from various teams of scientists in our research building such as engineering design, mechanical, electronic, or computer engineering. All subjects were voluntary participants. The 30 subjects carried out the experiment on the three graphic supports (PCP, CT, RC). Thus, we obtained 30*3=90 test results (the experiment respects a within-subject approach). The mean age of the subject was 30.9 years (SD=7.3). The gender distribution was $53.3 \%$ women and $46.7 \%$ men. We observed that only $3.3 \%$ of participants had already used a PCP, $66.7 \%$ a Radar Chart and $33.3 \%$ a combined table.

\section{Measurements}

Variables were either measured during the tests with the CamStudio (http://camstudio.org/) tool or collected through the final questionnaire $\left(n^{\circ} 2\right)$.

6.1 Description Of Variables 
The influence of the graph on trade-off assessment is measured with two variables: the time spent on decisionmaking - selecting an optimal solution - and the quality index for the selected design point or selected car (the quality index calculation is described in the next section). Also, we noted the number of actions performed to finally choose a car and the time spent between actions in order to identify the influence of the graph on the path. For us, the path refers to the user engagement as defined by Boy and colleagues: "By engagement, we specifically mean a user's investment in the exploration of a visualization." (Boy et al., 2015). "Action" refers to all interactions with the graphic tool. It uses the "brush", "filter" or "sorting" functions. Every action is an indication of the designer's mental activity (data mining). These four variables are collected during the scenario phase.

We used a questionnaire at the end of the experiment to obtain "subjective" measurements: Influence of the graph on the cognitive load and Influence of the graph on the level of confidence. To measure cognitive load, we chose the DALI method (Pauzié, 2008) which is the method which provides the greatest breakdown of the cognitive load through its questionnaire compared to NASA TLX or SWAT (visual effort, for example). We also adapted DALI to our case (DALI is designed for driving so we adapted the questions for the design selection). Answers to questions are given on a scale of 0 to 100. Finally, to determine the influence of the graph on the level of confidence, we used an adapted Aloysius et al. (2006) method. For this, we have two variables: Level of certainty in the chosen solution and the Preference for one graph. As for the cognitive load, answers are given on a scale of 0 to 100. This set of measures is summarized in Fig 10.

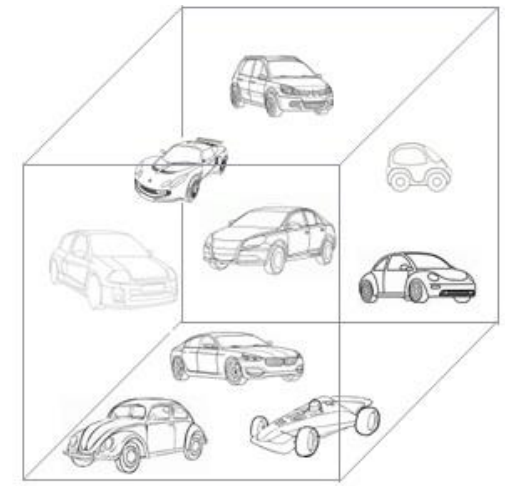

Design Space

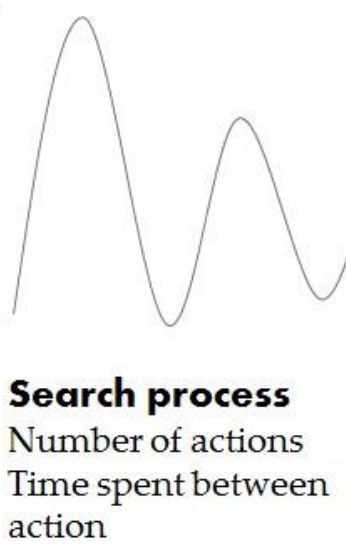
action

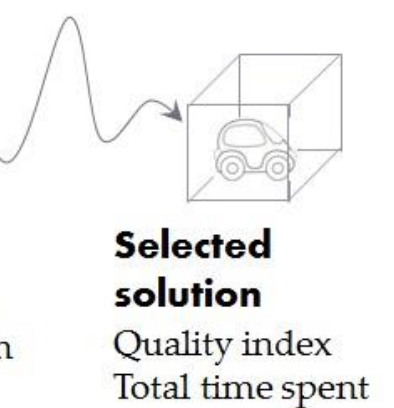

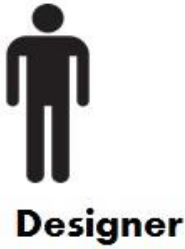

Cognitive load (perceived effort \& perceived stress) Confidence

Fig 10. The experiment's measurements

\subsection{Quality index}

As mentioned above, in all three scenarios, the subject was asked to explore possible solutions (design points) and select the ideal car according to the scenario. To do this, five performance variables have to be either maximized or minimized. There are a variety of performance metrics or quality indices with different uses. A number of works deal with metrics to compare observed Pareto solution sets (Wu \& Azarm, 2001) (Tang et al., 2005). There are also researchers who are interested in performance indices to compare Multi-Objective optimization algorithm quantitatively (Okabe et al., 2003). Overall, performance metrics are developed when simulations are run. In our case, there are no simulations, either from subjects or from us. We aim to automatically calculate an index to determine which graph allows designers to make the best decisions. In the following section, we describe the construction of a quality index linked to a design scenario from the Pareto dominance and a basic index.

\subsubsection{Pareto Dominance}

Considering a multi-objective problem such as:

$\min \left(F(x)=\left(f_{1}(x), f_{2}(x), \ldots, f_{n}(x)\right), n \geq 2\right.$ 
Abi Akle A., Minel S., Yannau B. (2016) 'Infarmation Visualization For Selection In Design By Shopping', Research in Engineering Design, 28(I), pp. 99-117. doi: I0.1007/s00163-0I6-0235-2

Where :

- $\quad x \in X$

- $\quad X$ is the decision space (or design parameter space)

- $\quad Y$ is the objective space (or performance space)

- $\quad$ And $\mathrm{Y}=\mathrm{F}(\mathrm{X})$

We define dominance as : $y$ dominates $\mathrm{z}$ if $\forall \mathrm{i} \in[1 \ldots \mathrm{n}], \mathrm{f}_{\mathrm{i}}(\mathrm{y}) \leq \mathrm{f}_{\mathrm{i}}(\mathrm{z})$ and $\exists \mathrm{k} \in[1 \ldots \mathrm{n}] \mid \mathrm{f}_{\mathrm{k}}(\mathrm{y})<\mathrm{f}_{\mathrm{k}}(\mathrm{z})$.

And the Pareto Dominance is defined by: One solution $\mathrm{x}^{\mathrm{p}} \in \mathrm{X}$ is Pareto-Optimal if $\nexists \mathrm{x} \in \mathrm{X} \mid \mathrm{x}$ dominates $\mathrm{x}^{\mathrm{p}}$

The representation of the set of Pareto-Optimal solutions in the objective space is called Pareto front. Finally, the performance evaluation of the dominated solutions is realized by calculating the Euclidian distance between the dominated solution and the Pareto front. In our case, we calculate the minimum distance between the dominated solution and non-dominated solutions $d$ (Equation 1).

$d=\min _{x}\left(\sqrt{\sum_{i=1}^{n}\left(x_{i}-x_{i}^{p}\right)^{2}}\right)$

- $\forall i \in[1 \ldots n]$, where $n$ is the number of performance variables.

- $\forall x \in X$ dominated solution and $x^{p} \in X$ non-dominated solution.

Then, for each scenario we apply the Pareto dominance principle and calculate the distance with the Pareto front for all the dominated solutions. Obviously, the distance allows us to compare the dominated solutions, but we need an additional index in order to compare the Pareto-Optimal solutions.

\subsubsection{Basic Index}

For each scenario, a basic index $i_{j}$ is calculated (Equation 2), after which a global basic index $i$ is calculated (Equation 3). The basic index is based on the Compromise Programming (CP) method, which appears to us the best fit to our case. $\mathrm{CP}$ assumes that any decision maker seeks a solution as close as possible to the ideal point. This is equivalent to minimizing the difference (i.e. distance) between utility at the ideal point and utility at a frontier point on the criteria map, a meaningful statement as minimizing distances to the utopia is the ethos of compromise programming.

$i_{j}=\frac{1}{n} \sum_{k=1}^{n}\left|\frac{f_{k}(P)-f_{k}(A)}{f_{k}(I)-f_{k}(A)}\right|, k=1 \ldots n$

$i=\left|\frac{i_{j}-i_{j_{\min }}}{i_{j_{\max }-i_{\min }}}\right|(3)$

Where $\mathrm{fk}$ is a performance variable ( $\mathrm{n}=5$ for each scenario). $\mathrm{fk}(\mathrm{P})$ is the value of design point $\mathrm{P}$ for the variable fk. And:

- If $f_{k}$ is maximized: $f_{k}(A)=$ the minimum value of $f_{k}$ and $f_{k}(I)=$ the maximum value.

- If $f_{k}$ is minimized: $f_{k}(A)=$ the maximum value of $f_{k}$ and $f_{k}(I)=$ the minimum value.

( $I$ for the Ideal and $A$ for the Anti-Ideal). We then calculate the global basic index $i$ with equation (3) so as to get a value below or equal to 1,1 being the best car considering the 5 variables of performance with an identical weighting. With this method, the three cases are comparable (cf. Fig11 a. and b.). 
Abi Akle A., Minel S., Yannou B. (2016) 'Information Visualization For Selection In Design By Shopping', Research in Engineering Design, 28(I), pp. 99-117, dai: 10.1007/s00163-016-0235-2

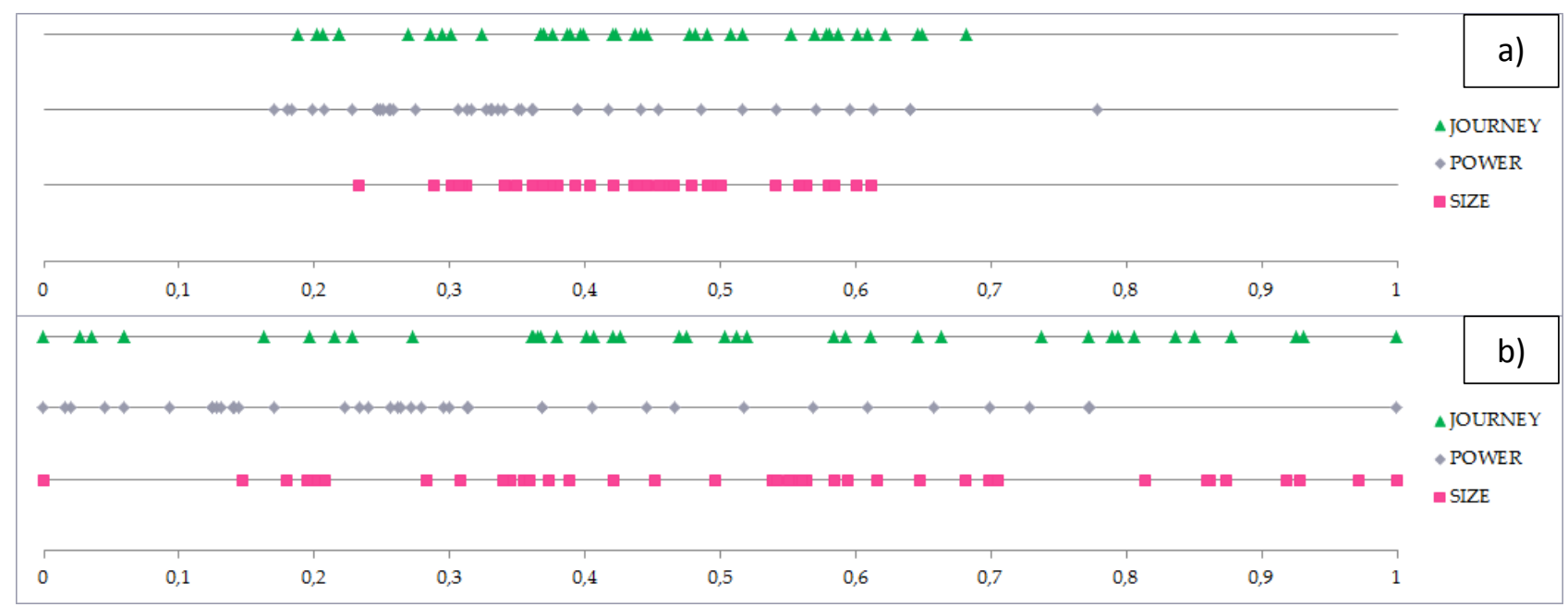

Fig 11. Illustration of the solution indexes: a) specific index and b) global basic index.

\subsubsection{Our Quality Index}

Our quality index distinguishes non-dominated from dominated solutions. It allows non-dominated solutions to be favored and dominated solutions to be "penalized".

The quality index for the non-dominated solutions is the basic index rescaled from 0 to 1 . Hence, a quality index is equal to 1 for the best and 0 for the worst solution in the set of non-dominated.

The quality index for dominated solutions corresponds to the distance to the Pareto front multiplied by (-1). Thus, the dominated solutions receive a negative quality index. The closest solution to the Pareto front receives a quality index close to 0 and the solution furthest from the Pareto Front receives the most "negative" quality index.

\section{Results}

We use 8 variables for 6 experimental measurements ( 3 variables for the cognitive load): Time to completion (TIME); Quality index (QUALITY); Number of actions (NBR_ACTION); Time spent between actions (TIME_ACTION); Cognitive load: Effort of attention (ATTENTION); Visual effort (VISUAL);Perceived stress (STRESS); and finally Level of certainty (CERTAINTY).

First of all, we check if there are any "scenario effects" and/or "learning effects" according to the sequence order through the experiment.

\subsection{Scenario and learning effects}

We have a sample of $\mathrm{N}=30$ subjects and we are in a within approach (3 groups/ scenarios /sequences). Also, all measured variables during the test are quantitative. Therefore, we apply the ANOVA-within statistical test. The results are shown in Table 1.

Table 1. ANOVA results for scenario and learning effects

\begin{tabular}{|l|l|l|}
\hline & ANOVA results for scenario effect & ANOVA results for learning effect \\
\hline TIME & $\mathrm{F}(2,58)=0.42 \mathrm{p}=0.66$ & $\mathrm{~F}(2,58)=5.91 \mathrm{p}<0.01$ \\
\hline QUALITY & $\mathrm{F}(2,58)=2.43 \mathrm{p}<0.10$ & $\mathrm{~F}(2,58)=0.58 \mathrm{p}=0.57$ \\
\hline NBR_ACTION & $\mathrm{F}(2,58)=1.59 \mathrm{p}=0.21$ & $\mathrm{~F}(2,58)=1.16 \mathrm{p}=0.32$ \\
\hline
\end{tabular}


Abi Akle A., Minel S., Yannau B. (2016) 'Infarmation Visualization For Selection In Design By Shopping', Research in Engineering Design, 28(I), pp. 99-117, doi: 10.1007/s00163-0I6-0235-2

\begin{tabular}{|l|l|l|}
\hline TIME_ACTION & $\mathrm{F}(2,58)=0.20 \mathrm{p}=0.82$ & $\mathrm{~F}(2,58)=0.66 \mathrm{p}=0.54$ \\
\hline ATTENTION & $\mathrm{F}(2,58)=0.97 \mathrm{p}=0.39$ & $\mathrm{~F}(2,58)=1.23 \mathrm{p}=0.30$ \\
\hline VISUAL & $\mathrm{F}(2,58)=0.66 \mathrm{p}=0.52$ & $\mathrm{~F}(2,58)=0.91 \mathrm{p}=0.41$ \\
\hline STRESS & $\mathrm{F}(2,58)=1.24 \mathrm{p}=0.30$ & $\mathrm{~F}(2,58)=1.48 \mathrm{p}=0.24$ \\
\hline CERTAINTY & $\mathrm{F}(2,58)=0.48 \mathrm{p}=0.62$ & $\mathrm{~F}(2,58)=1.18 \mathrm{p}=0.32$ \\
\hline
\end{tabular}

The results of these tests concerning the scenario effect are not significant. So there is no "scenario effect" on the 8 variables. The results of the tests concerning the learning effect, however, show a significant difference for the time to completion (see Fig. 12).

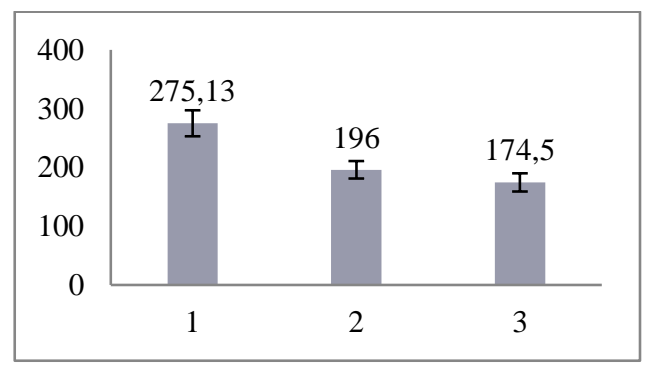

Fig 12.Mean and Standard Error for the variable TIME during each sequence

So we have to perform a post-hoc analysis thus we carry out t-test pairwise comparison:

- $\quad$ [sequence 1] vs[sequence 2] $\mathrm{t}(29)=2.30 \mathrm{p}<0.03$

- $\quad$ [sequence 1] vs[sequence 3] $\mathrm{t}(29)=2.86 \mathrm{p}<0.01$

- [sequence 2] vs[sequence 3] $\mathrm{t}(29)=1.04 \mathrm{p}<0.31$

The results of the t-tests show that the time to completion is longer in sequence 1 than in sequences 2 and 3 . This means for the rest of the analysis that we should split data between sequence 1 and sequence 2 and 3 when comparing time to completion with the 3 graphs.

\subsection{Effect of Graphs}

\subsubsection{Influence of the Graph on the selected solution (TIME \& QUALITY)}

In order to compare the response time between the three graphs during the sequence 1, we apply the ANOVAbetween statistical test with a sample of $\mathrm{N}=30$ subjects. The results are not significant. We obtain $\mathrm{F}(2,27)=0.99$ and $\mathrm{p}=0.39$. For sequences 2 and 3 , we apply several $\mathrm{t}$-tests because we are in a within approach ( 2 groups i.e. 2 graphs using in the sequences 2 and 3 ) and we have a sample of $\mathrm{N}=10$ subjects: $[\mathrm{RC}] \mathrm{vs}[\mathrm{CT}]: \mathrm{t}(9)=2.01 \mathrm{p}<0.08$; $[P C P] v s[C T]: t(9)=0.19 p<0.85$ and $[P C P] v s[R C]: t(9)=0.68 p<0.51$ (see Fig. 13).

The results of these t-tests are not significant. There are therefore no significant differences between the three graphs for time completion. 
Abi Akle A., Minel S., Yannau B. (2016) 'Infarmation Visualization For Selection In Design By Shopping', Research in Engineering Design, 28(I), pp. 99-117, doi: ID.I007/s00163-0I6-0235-2
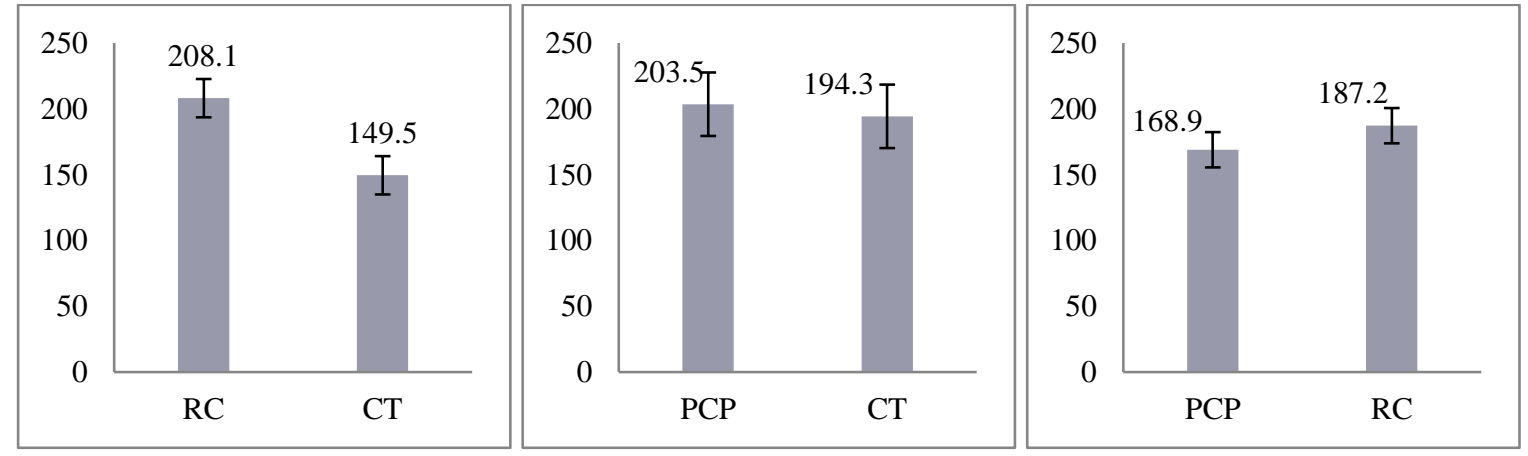

Fig 13. Mean and Standard Error for the variable TIME during sequences 2 and 3

Then, we obtain $F(2,58)=0.03$ and $p=0.98$ for the quality index. The results for trade-offs are not significant. There are therefore no significant differences between the three graphs for the selected solution.

Indeed, we observe good results (i.e. high quality index values) for the three graphs: $\mathrm{i}=0.78$ with $\mathrm{PCP}, \mathrm{i}=0.77$ with $\mathrm{RC}$ and $\mathrm{i}=0.77$ with $\mathrm{CT}$ (see Fig 14).

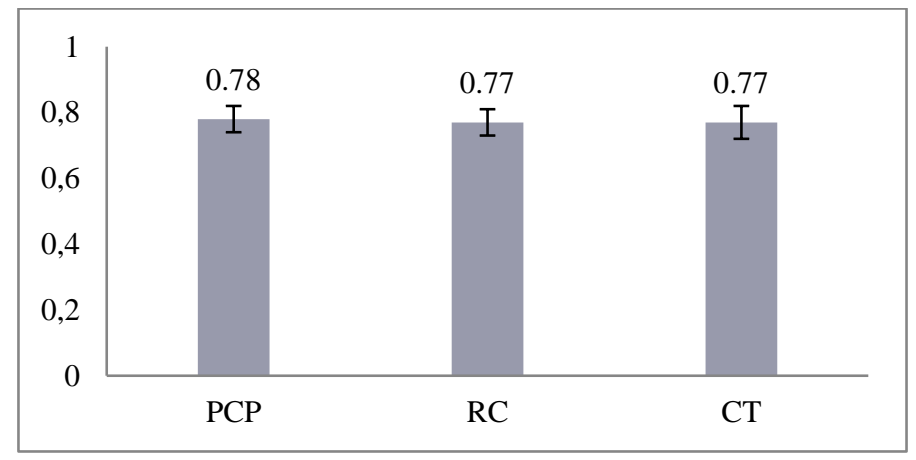

Fig 14. Mean and Standard Error for the variable QUALITY

\subsubsection{Influence of the graph on the path (NBR_ACTION \& TIME_ACTION)}

As in the previous section, we have a sample of $\mathrm{N}=30$ subjects and it is a within approach ( 3 groups). Also, all measured variables during the test are quantitative. Therefore, we apply an ANOVA within statistical test (and the T-test for the post-hoc analysis).

The results for the performance of data mining are significant because we obtain $\mathrm{F}(2,58)=14.1$ and $\mathrm{p}<0.01$ for the number of actions carried out and $F(2,58)=10.7$ and $\mathrm{p}<0.01$ for the average time between actions. So we perform a post-hoc analysis: t-test pairwise comparison (see Table 2).

Table 2. Results for the t-test for the number of actions and the time between actions

\begin{tabular}{|l|l|l|}
\hline T-test pairwise comparison & for the number of actions & for the time between actions \\
\hline$[\mathrm{PCP}]$ vs $[\mathrm{RC}]$ & $\mathrm{t}(29)=3.81 \quad \mathrm{p}<0.01$ & $\mathrm{t}(29)=3.90 \quad \mathrm{p}<0.01$ \\
\hline$[\mathrm{PCP}]$ vs $[\mathrm{CT}]$ & $\mathrm{t}(29)=4.22 \mathrm{p}<0.01$ & $\mathrm{t}(29)=5.02 \quad \mathrm{p}<0.01$ \\
\hline$[\mathrm{RC}]$ vs $[\mathrm{CT}]$ & $\mathrm{t}(29)=0.46 \mathrm{p}=0.65$ & $\mathrm{t}(29)=1.92 \quad \mathrm{p}<0.07$ \\
\hline
\end{tabular}

The results of these tests show that the PCP is the most efficient for data mining with an action number equal to 9.67 and an average time between actions of 26.19 seconds compared to 3.97 action numbers for RC and 3.60 for CT and 72.96 seconds between actions for RC and 50.29 seconds for CT (see Fig 15). 
Abi Akle A., Minel S., Yannou B. (2016) 'Information Visualization For Selection In Design By Shopping', Research in Engineering Design, 28(I), pp. 99-117, doi: 10.1007/s00163-016-0235-2

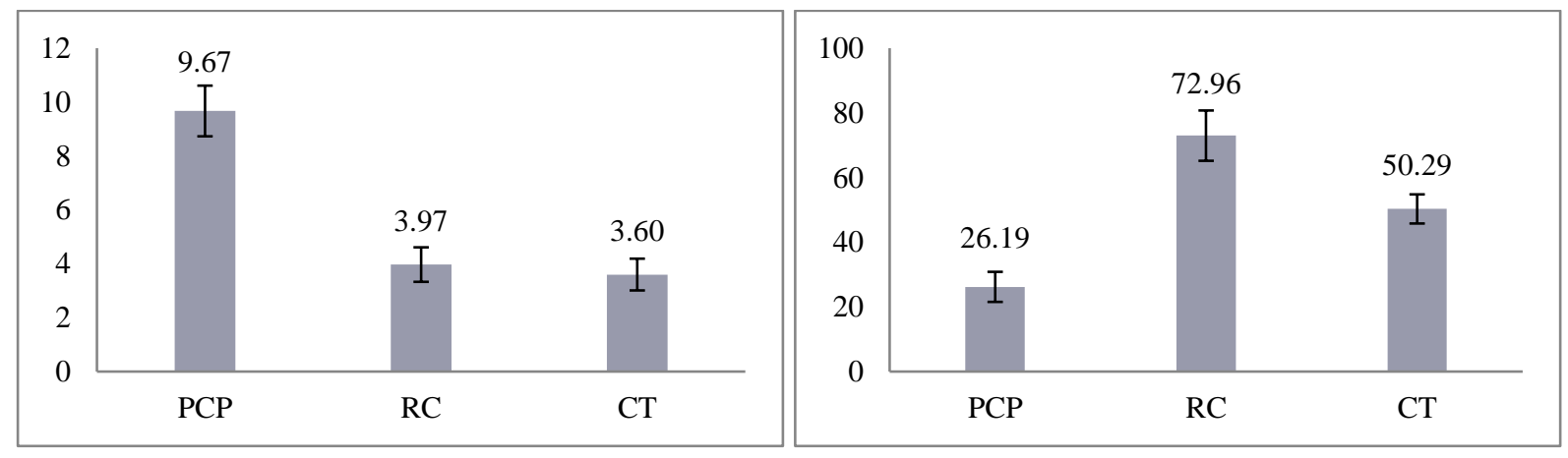

Fig 15. Mean and Standard Error for the variable NBR_ACTION (on the left) and TIME_ACTION (on the right)

\subsubsection{Graph's influence on the designer}

In this analytical stage, we use Friedman (and Wilcoxon) for statistical analysis $(\mathrm{N}=30)$ because the variables are ordinal (qualitative) and we consider a significance level $\alpha=5 \%$.

Cognitive load (ATTENTION, VISUAL \& STRESS)

The cognitive measurement is divided into three indicators: effort of attention, visual effort and perceived stress. The results for the three indicators are significant. We obtain csqr $=8.87, \mathrm{df}=2$ and $\mathrm{p}<0.01$ for the effort of attention, csqr $=8.15, \mathrm{df}=2$ and $\mathrm{p}<0.02$ for the visual effort and csqr=19.27, $\mathrm{df}=2$ and $\mathrm{p}<0.01$ for the perceived stress. So we perform a post-hoc analysis: Wilcoxon pairwise comparison (see Table 3).

Table 3. Results of the Wilcoxon tests for the three indicators of the cognitive load

\begin{tabular}{|l|l|l|l|}
\hline $\begin{array}{l}\text { Wilcoxon pairwise } \\
\text { comparison }\end{array}$ & ATTENTION & VISUAL & STRESS \\
\hline$[\mathrm{PCP}]$ vs $[\mathrm{RC}]$ & $\mathrm{W}=-193 \mathrm{p}<0.03$ & $\mathrm{~W}=-270 \mathrm{p}<0.01$ & $\mathrm{~W}=-254 \mathrm{p}<0.01$ \\
\hline$[\mathrm{PCP}]$ vs $[\mathrm{CT}]$ & $\mathrm{W}=57 \mathrm{p}=0.28$ & $\mathrm{~W}=6 \mathrm{p}=0.48$ & $\mathrm{~W}=144 \mathrm{p}>0.05$ \\
\hline$[\mathrm{RC}]$ vs $[\mathrm{CT}]$ & $\mathrm{W}=201 \mathrm{p}<0.04$ & $\mathrm{~W}=205 \mathrm{p}<0.02$ & $\mathrm{~W}=296 \mathrm{p}<0.01$ \\
\hline
\end{tabular}

The results of these tests show a significant difference for RC with the most effort with 63.28/100 attention (compared to 51.44 for PCP and 48.61 for CT), visual effort of 67.67/100 (compared to 54.39 for PCP and 53.00 for CT) and a perceived stress of $64.12 / 100$ (compared to 48.83 for PCP and 41.13 for CT). We cannot conclude any difference between PCP and CT.

\section{Confidence (CERTAINTY \& PREFERENCE)}

The confidence measurement consists of two indicators: the level of certainty and preference (for path and to select one solution).

We apply the Friedman test and the results for the level of certainty are not significant. We obtain csqr=1.22, $\mathrm{df}=2$ and $\mathrm{p}=0.54$. We therefore cannot conclude that there is a significant difference between the three graphs for this indicator $(\mathrm{PCP}=55.61 / 100 ; \mathrm{RC}=50.44 / 100$ and $\mathrm{CT}=63.83 / 100)$.

Finally, the graph preference for the design process' selection phase is tested with two modalities: the preference of one graph for path; and selecting one solution. Here, we use the Friedman test for statistical analysis because the answers are ranks and we have 3 within groups.

The results for the preference are significant. We obtain csqr $=16.47, \mathrm{df}=2$ and $\mathrm{p}<0.01$ for data mining and csqr=9.8, $\mathrm{df}=2$ and $\mathrm{p}<0.01$ for decision-making. There is a difference between the three graphs for these two modalities. So, we perform a post-hoc analysis: Wilcoxon signed-rank test pairwise comparison (as $\mathrm{N}=30>20$, we consider the $\mathrm{W}$-value). For $\mathrm{N}=30$ at $\mathrm{p}>0.05, \mathrm{~W}$-value $=137$ (Table 4). 
Abi Akle A., Minel S., Yannau B. (2016) 'Infarmation Visualization For Selection In Design By Shopping', Research in Engineering Design, 28(I), pp. 99-117, doi: I0.1007/s00163-0I6-0235-2

Table 4. Results of the Wilcoxon signed-rank test for the two indicators of preference

\begin{tabular}{|l|l|l|}
\hline $\begin{array}{l}\text { Wilcoxon signed-rank test pairwise } \\
\text { comparison }\end{array}$ & for path & to select one solution \\
\hline$[\mathrm{PCP}]$ vs $[\mathrm{RC}]$ & $\mathrm{W}$-value $=65(\mathrm{p}<0.05)$ & $\mathrm{W}$-value $=91(\mathrm{p}<0.05)$ \\
\hline$[\mathrm{PCP}]$ vs $[\mathrm{CT}]$ & W-value $=206$ & $\mathrm{~W}$-value $=189$ \\
\hline$[\mathrm{RC}]$ vs $[\mathrm{CT}]$ & W-value $=85(\mathrm{p}<0.05)$ & $\mathrm{W}$-value $=132(\mathrm{p}<0.05)$ \\
\hline
\end{tabular}

The results of these tests show a significant difference for $\mathrm{RC}$ which is the least preferred graph with a rank $=2.6$ for data mining (compared to 1.6 for PCP and 1.8 for $\mathrm{CT}$ ) and rank=2.4 to select one solution (compared to 1.6 for PCP and 1.9 for $\mathrm{CT}$ ).

\subsection{Correlations}

The last part of the analysis is devoted to finding correlations between TIME and QUALITY, TIME and CERTAINTY and TIME and cognitive load (ATTENTION, VISUAL \& STRESS). Firstly, we realize the measurements on all data, then per sequence and per graph. We use the Pearson product-moment correlation coefficient $(\mathrm{R})$ and the coefficient of determination $\left(\mathrm{R}^{2}\right)$. Moreover, we use the value of $\mathrm{t}$ associated with the calculated value of $\mathrm{R}$, along with the corresponding $\mathrm{p}$-value to assess the significance of any particular instance of R.

\section{TIME vs QUALITY}

The results obtained show that there is no correlation between the time to completion and the quality of the selected solution.

\section{TIME vs CERTAINTY}

We obtain significant results for the correlation between TIME and CERTAINTY (see Table 5). The measurement across all the data gives us a negative correlation with a 3.35\% variability in TIME linked with variability in CERTAINTY.

Table 5. Significant results for correlations between TIME and CERTAINTY

\begin{tabular}{|c|c|c|c|c|c|c|c|c|}
\hline Data & N & $\begin{array}{c}\text { Mean } \\
\text { CERTAINTY }\end{array}$ & $\begin{array}{c}\text { Mean } \\
\text { TIME }\end{array}$ & $\mathbf{R}$ & $\mathbf{R}^{\mathbf{2}}$ & $\mathbf{t}$ & $\mathbf{d f}$ & p-value \\
\hline All & 90 & 56.63 & 215.21 & -0.18 & 0.03 & -1.75 & 88 & 0.04 \\
\hline CT & 30 & 63.83 & 211.00 & -0.63 & 0.40 & -4.32 & 28 & $<0.01$ \\
\hline
\end{tabular}

Unfortunately, this link is very low. However, the measurement of the data linked to the CT graph gives us a negative correlation with $40 \%$ of variability in TIME linked with variability in CERTAINTY (see Fig 16). So, there is a link (a trend) between time and the confidence of the subject when using the Combined Table: the longer the particpants take, the lower their level of confidence. 


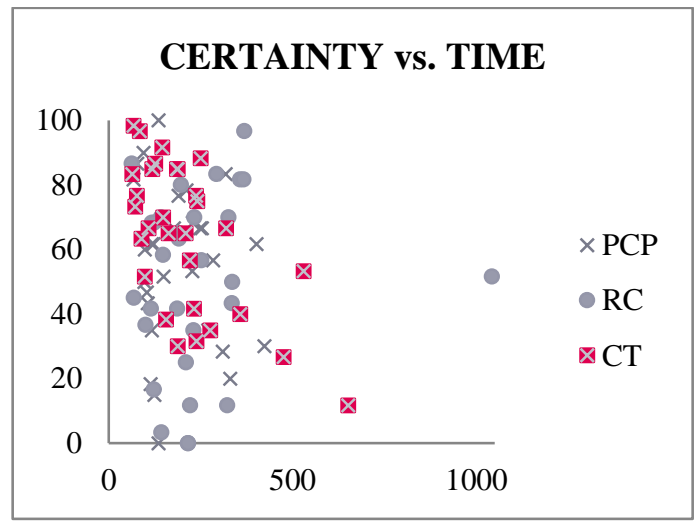

Fig 16. Plots of CERTAINTY vs. TIME per graphs

TIME vS ATTENTION

Table 6. Significant results for correlations between TIME and ATTENTION

\begin{tabular}{|c|c|c|c|c|c|c|c|c|}
\hline Data & $\mathbf{N}$ & $\begin{array}{c}\text { Mean } \\
\text { ATTENTION }\end{array}$ & $\begin{array}{c}\text { Mean } \\
\text { TIME }\end{array}$ & $\mathbf{R}$ & $\mathbf{R}^{\mathbf{2}}$ & $\mathbf{t}$ & $\mathbf{d f}$ & p-value \\
\hline RC & 30 & 63.28 & 241.87 & -0.35 & 0.13 & -2 & 28 & $<0.03$ \\
\hline CT & 30 & 48.61 & 211.00 & 0.57 & 0.32 & 3.64 & 28 & $<0.01$ \\
\hline
\end{tabular}

We obtain significant results for the correlation between TIME and ATTENTION (see Table 6). The measurements on the data linked to the RC and CT graphs give correlations. For the Radar Chart, it appears a negative correlation with $12.5 \%$ of variability in TIME linked with variability in ATTENTION (low link) and a positive correlation with $32 \%$ of variability in TIME linked with variability in ATTENTION for the Combined Table (see Fig 17).

The results are unexpected. When using Radar chart, more the participants take time less they have effort of attention whereas more the participants take time more they have effort of attention when using the Combined Table.

TIME vS VISUAL

We obtain one significant result for the correlation between TIME (mean= 210.97) and VISUAL (mean= 53) with $\mathrm{N}=30, \mathrm{R}^{2}=0.17, \mathrm{t}=2.36$ and $\mathrm{p}=0.01$. The measurement on the data linked to the $\mathrm{CT}$ graph gives us a positive correlation with $16.6 \%$ of variability in TIME linked with variability in VISUAL (see Fig 17). So, there is a link (low) between time and the visual effort when using the Combined Table: More the participants take time more they have visual effort.

\section{TIME vs STRESS}

Once again, we obtain one significant result for the correlation between TIME (mean=211.00) and STRESS (mean= 41.13) with $\mathrm{N}=30, \mathrm{R}^{2}=0.23, \mathrm{t}=2.88$ and $\mathrm{p}<0.01$. The measurement on the data linked to the $\mathrm{CT}$ graph gives us a positive correlation with $22.9 \%$ of variability in TIME linked with variability in STRESS (see Fig 17). So, there is a link between time and the perceived stress when using the Combined Table: More the participants take time more they have stress. 


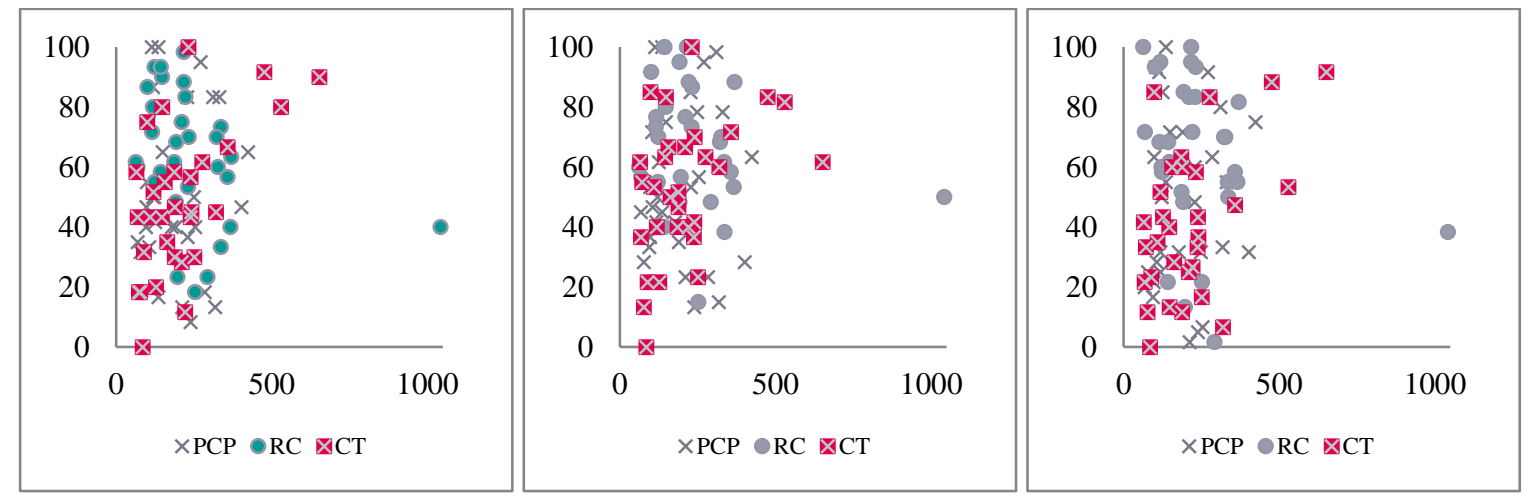

Fig 17. Plots of ATTENTION vs. TIME (on the left), VISUAL vs. TIME (on the center) and STRESS vs. TIME (on the right)

\subsection{Synthesis of results}

To sum up our results, we have a greater performance for the "path" (ie. data mining) with the graph Parallel Coordinates Plot (PCP). There is no distinction between the three graphs for the selected solution (both quality index and time indicators). Furthermore, the designer is less satisfied than with the graph Radar Chart (RC). The results are summarized in Table 7.

The correlation analysis enables us firstly to note that, overall, the selection of a good design is not related to the time that participants spent on the graphs. Moreover, we observe, on the use of CT, there is a link, a trend between the time to completion and cognitive workload and time and trust. It seems that time is linked to the cognitive effort by the participants. Conversely, participants take more time and more confidence decreases. More broadly, it suggests to us that the participants experienced an important cognitive workload are those who remained longer on the graph. Reasonably, we find that the duration of the exercise is linked to the difficulty perceived by the subject, for the CT. The results are reversed for the RC. Participants who spent few time on the $\mathrm{RC}$ have felt a strong effort of attention. The results for the RC are difficult to interpret, perhaps should we promote designers to spend more time on the $\mathrm{RC}$ in order to reduce the effort of attention. At last, in line with the cognitive workload results, participants who spent time on the graph CT have little confidence in their selected solution.

Finally, we should therefore conclude that the Parallel Coordinates Plot (PCP) is the best graphic support to help designers select one optimal solution whilst exploring the design space.

Table 7. Synthesis of results

\begin{tabular}{|l|l|l|l|}
\hline & Path & Selected solution & Designer satisfaction \\
\hline Best graphs & PCP & \multirow{2}{*}{ none } & PCP $\equiv$ CT \\
\cline { 4 - 4 } & & RC \\
\hline
\end{tabular}

\section{Conclusion \& Discussion}

In conclusion, our experiment enables us to make certain recommendations regarding the choice of graph for the selection phase in Design by Shopping. More specifically, we deliver a directive for the choice of a graph representing design points to efficiently select an optimal solution in a set of feasible solutions defined by their design and performance value vectors.

Indeed, our results show that it is more efficient to use the Parallel Coordinate Plot, which performs better in our experiment. It is worth noting that our recommendations apply design multi-criteria decisions or, in other words, trade-offs between conflicting objectives to obtain an optimal solution. Finally, we propose using two graphs on the same screen. The Parallel Coordinate Plot is particularly useful for data mining and selecting an alternative, 
while the combined table specifically provides detailed information (eg. specific values). Nevertheless, both graphs must match (linked views) ie. if a filter is applied to one graph, the data must be automatically filtered on the second graph.

Eikenes and Morrison (2010) argue and show that the interface is not just a flat layer between the user and computer, but is rather a complex, mediating, cultural artefact. Thus, appropriate distinctions between designer profiles, such as expert designer or novice designer, can help improve results. As shown by Wolf et al. (Wolf et $a l ., 2009)$, there are procedural differences in how novices and experts use multi-dimensional data visualization and exploration tools when solving an engineering design problem. In the same way, increasing the training phase could substantially enhance the difference between the three graphs for the design selection phase because we observe a poor use of the PCP (only $3.3 \%$ of participants have already used a PCP). In fact, Wolf et al. (Wolf et al., 2011) have already shown the importance of training for the entire process of exploring the trade space. In addition, we believe that an indicator after the training phase could provide valuable information about the result, thus enabling the participant to measure the graph's practical level. This would, for instance, allow us to identify a lack of practice at the origin of non-optimal decisions, for instance.

Since knowledge of the three graphs is very heterogeneous (3.3\% of participants have already used a PCP, $66.7 \%$ a Radar Chart and $33.3 \%$ a combined table), we cannot impose a time limit, because the results would reflect a lack of use of graphical tools. Thus, greater training which measures practice would allow us to add a time limit and reveal richer results.

Obviously, our experiment focuses on the selection phase; it would be advisable to develop this approach by identifying graphs adapted to designers for the entire process. Firstly, this will test whether the PCP is the best graph for the selection phase included in the process of exploring the design space, ie. following the generation of design points - reduction of space design loop. Secondly, it will enable us to verify that the PCP is a graph that can support all of the phases of the process in an effective manner. Finally, it may be useful to envisage the use of graphical tools in a collaborative framework such as that used in (Canbaz et al., 2012, 2013).

\section{Acknowledgments}

We wish to thank all those took part in our experiment.

Conflict of interest: The authors declare that they have no conflict of interest.

\section{References}

1. Abi Akle, A., Minel, S., Yannou, B., "Change the visual alert display to improve the decision making time: industrial systems supervision case study”,Proceeding in CONFERE'13,Biarritz, France, 2013.

2. Agrawal, G., Lewis, K., Chugh, K., Huang, C. H., Parashar, S., \& Bloebaum, C. L. (2004, August). Intuitive visualization of Pareto frontier for multi-objective optimization in n-dimensional performance space. In 10th AIAA/ISSMO multidisciplinary analysis and optimization conference, Albany, NY, Paper No. AIAA Vol. 2004-4434.

3. Aloysius, J. A., Davis, F. D., Wilson, D. D., Ross Taylor, A., \& Kottemann, J. E. (2006). User acceptance of multi-criteria decision support systems: The impact of preference elicitation techniques. European Journal of Operational Research, 169(1), 273-285.

4. Balling, R. (1999, May). Design by shopping: A new paradigm?. In Proceedings of the Third World Congress of structural and multidisciplinary optimization (WCSMO-3) (Vol. 1, pp. 295-297).

5. Barron, K., Simpson, T. W., Rothrock, L., Frecker, M., Barton, R. R., \& Ligetti, C. (2004, January). Graphical user interfaces for engineering design: impact of response delay and training on user performance. In ASME 2004 International Design Engineering Technical Conferences and Computers 
Abi Akle A., Minel S., Yannou B. (20I6) 'Information Visualization For Selection In Design By Shopping', Research in Engineering Design, 28(I), pp. 99-II7, dai: 10.1007/s00163-016-0235-2

and Information in Engineering Conference, Salt Lake City, UT, ASME, Paper No. DETC2004/DTM-57085.

6. Boy, J., Eveillard, L., Detienne, F., \& Fekete, J. D. (2016). Suggested Interactivity: Seeking Perceived Affordances for Information Visualization. Visualization and Computer Graphics, IEEE Transactions on, 22(1), 639-648.

7. Canbaz, B. (2013). Preventing and resolving design conflicts for a collaborative convergence in distributed set-based design (Doctoral dissertation, Ecole Centrale Paris).

8. Canbaz, B., Yannou, B., \& Yvars, P. A. (2012, August). Constraint programming simulation of a distributed set-based design framework with control indicators. In ASME 2012 International Design Engineering Technical Conferences and Computers and Information in Engineering Conference, Chicago, Illinois, USA, Paper No. DETC2012-70857, pp. 1239-1248.

9. Cook, D., Hofmann, H., Lee, E. K., Yang, H., Nikolau, B., \& Wurtele, E. (2007). Exploring gene expression data, using plots. Journal of Data Science, 5(2), 151-182.

10. Daskilewicz, M., and German, B. (2009). Aspects of Effective Visualization of Multidimensional Design Spaces. In 9th AIAA Aviation Technology, Integration, and Operations Conference (ATIO), 21 23 September 2009, Hilton Head, South Carolina, Paper No. AIAA Vol. 2009-6929.

11. Daskilewicz, M. J., \& German, B. J. (2012). Rave: A computational framework to facilitate research in design decision support. Journal of computing and information science in engineering, 12(2), 021005.

12. Eddy, J., \& Lewis, K. E. (2002, January). Visualization of multidimensional design and optimization data using cloud visualization. In ASME 2002 International Design Engineering Technical Conferences and Computers and Information in Engineering Conference (pp. 899-908). American Society of Mechanical Engineers, Montreal, Canada.

13. Eikenes, J. O. H., \& Morrison, A. (2010). Navimation: Exploring time, space \& motion in the design of screen-based interfaces. International Journal of Design, 4(1), 1-16.

14. Feather, M., Cornford, S., Hicks, K., Kiper, J., \& Menzies, T. (2008). Application of a broad-spectrum quantitative requirements model to early-lifecycle decision making. IEEE Software, 1673-1680.

15. Ferringer, M. P., Spencer, D. B., \& Reed, P. (2009, May). Many-objective reconfiguration of operational satellite constellations with the large-cluster epsilon non-dominated sorting genetic algorithm-II. In Evolutionary Computation, 2009. CEC'09. IEEE Congress on (pp. 340-349). IEEE.

16. Gettinger, J., Kiesling, E., Stummer, C., \& Vetschera, R. (2013). A comparison of representations for discrete multi-criteria decision problems. Decision support systems, 54(2), 976-985.

17. Inselberg,A. (2009). Parallel Coordinates: Visual Multidimensional Geometry and Its Applications, Springer, Dordrecht, 2009.

18. Kanukolanu, D., Lewis, K. E., \& Winer, E. H. (2006). A multidimensional visualization interface to aid in trade-off decisions during the solution of coupled subsystems under uncertainty. Journal of computing and information science in engineering, 6(3), 288-299.

19. Keim, D. A. (2000). Designing pixel-oriented visualization techniques: Theory and applications. Visualization and Computer Graphics, IEEE Transactions on, 6(1), 59-78.

20. Kollat, J. B., \& Reed, P. (2007). A framework for visually interactive decision-making and design using evolutionary multi-objective optimization (VIDEO). Environmental Modelling \& Software, 22(12), 1691-1704 
Abi Akle A., Minel S., Yannou B. (20I6) 'Information Visualization For Selection In Design By Shopping', Research in Engineering Design, 28(I), pp. 99-117, dai: 10.1007/s00163-016-0235-2

21. Ligetti, C., Simpson, T. W., Frecker, M., Barton, R. R., \& Stump, G. (2003). Assessing the impact of graphical design interfaces on design efficiency and effectiveness. Journal of Computing and Information Science in Engineering, 3(2), 144-154.

22. Long, F. (2009, May). Real or imaginary: The effectiveness of using personas in product design. In Proceedings of the Irish Ergonomics Society Annual Conference (pp. 1-10). Irish Ergonomics Society Dublin.

23. Malak Jr, R. J., Aughenbaugh, J. M., \& Paredis, C. J. (2009). Multi-attribute utility analysis in set-based conceptual design. Computer-Aided Design, 41(3), 214-227.

24. Miettinen, K. (2014). Survey of methods to visualize alternatives in multiple criteria decision making problems. OR spectrum, 36(1), 3-37.

25. Miller, S. W., Simpson, T. W., Yukish, M. A., Bennett, L. A., Lego, S. E., \& Stump, G. M. (2013, August). Preference Construction, Sequential Decision Making, and Trade Space Exploration. In ASME 2013 International Design Engineering Technical Conferences and Computers and Information in Engineering Conference, Portland, Oregon, USA, Paper No. DETC2013-13098, pp. V03AT03A014.

26. Naim, A. M., Chiu, P. W., Bloebaum, C., \& Lewis, K. (2008, September). Hyper-radial visualization for multi-objective decision-making support under uncertainty using preference ranges: the PRUF method. In 12th AIAA/ISSMO multidisciplinary analysis and optimization conference, Victoria, British Columbia Canada, Paper No. AIAA Vol. 2008-6087.

27. Narayanan, R. L. (2001). Human-in-the-Loop Simulations: Methods and Practice. S. (Eds.) 2011, VIII, $261 \mathrm{p}$.

28. Nekolny, B., Richardson, T., \& Winer, E. (2010). Visual Design Space Exploration using Contextual Self-Organizing Maps. In 13th AIAA/ISSMO Multidisciplinary Analysis and Optimization Conference, Forth Worth, Texas, Paper No. AIAA Vol. 2010-9326.

29. Okabe, T., Jin, Y., \& Sendhoff, B. (2003, December). A critical survey of performance indices for multi-objective optimisation. In Evolutionary Computation, 2003. CEC'03. The 2003 Congress on (Vol. 2, pp. 878-885). IEEE.

30. Otto, K. N., \& Antonsson, E. K. (1993). The method of imprecision compared to utility theory for design selection problems. Design Theory and Methodology-DTM'93, 167-173.

31. Pauzie, A. (2008). A method to assess the driver mental workload: the driving activity load index (DALI). IET Intelligent Transport Systems, 2(4), 315-322.

32. Rangavajhala, S. (2007). Decision Making in Design Under uncertainty with multiobjective Robust Design Optimization 205p, Rensselaer Polytechnic Institute, Troy, NY.

33. Rothrock, L., \& Narayanan, S. (Eds.). (2011). Human-in-the-loop simulations. London, UK: Springer.

34. Saary, M. J. (2008). Radar plots: a useful way for presenting multivariate health care data. Journal of clinical epidemiology, 61(4), 311-317.

35. Scott, M. J., \& Antonsson, E. K. (2000, September). Using indifference points in engineering decisions. In Proceedings of ASME Design Engineering Technical Conferences, Baltimore, USA, Paper No. DETC2000/DTM-14559.

36. Scott, M. J., \& Antonsson, E. K. (2005). Compensation and weights for trade-offs in engineering design: beyond the weighted sum. Journal of Mechanical Design, 127(6), 1045-1055. 
Abi Akle A., Minel S., Yannau B. (2016) 'Infarmation Visualization For Selection In Design By Shopping', Research in Engineering Design, 28(I), pp. 99-117, doi: 10.1007/s00163-016-0235-2

37. Shanteau, J. (1992). Competence in experts: The role of task characteristics. Organizational behavior and human decision processes, 53(2), 252-266.

38. Shneiderman, B. (1992). Tree visualization with tree-maps: 2-d space-filling approach. ACM Transactions on graphics (TOG), 11(1), 92-99.

39. Shocker, A. D., Ben-Akiva, M., Boccara, B., \& Nedungadi, P. (1991). Consideration set influences on consumer decision-making and choice: Issues, models, and suggestions. Marketing letters, 2(3), 181197.

40. Simpson, T. W., Barron, K., Rothrock, L., Frecker, M., Barton, R. R., \& Ligetti, C. (2007). Impact of response delay and training on user performance with text-based and graphical user interfaces for engineering design. Research in Engineering Design, 18(2), 49-65.

41. Simpson, T. W., Spencer, D. B., Yukish, M. A., \& Stump, G. (2008, September). Visual steering commands and test problems to support research in trade space exploration. In 12th AIAA/ISSMO Multidisciplinary Analysis and Optimization Conference, Victoria, British Columbia Canada, Paper No. AIAA Vol. 2008-6085.

42. Stump, G., Lego, S., Yukish, M., Simpson, T. W., \& Donndelinger, J. A. (2009). Visual steering commands for trade space exploration: User-guided sampling with example. Journal of Computing and Information Science in Engineering, 9(4), 044501.

43. Stump, G., Yukish, M., Martin, J. D., \& Simpson, T. W. (2004, August). The ARL trade space visualizer: An engineering decision-making tool. In 10th AIAA/ISSMO Multidisciplinary Analysis and Optimization Conference, Albany, NY, Paper No. AIAA Vol. 2004-4568.

44. Tang, Y., Reed, P., \& Wagener, T. (2005). How effective and efficient are multiobjective evolutionary algorithms at hydrologic model calibration?. Hydrology and Earth System Sciences Discussions Discussions, 2(6), 2465-2520.

45. Wilson, T. D., \& Schooler, J. W. (1991). Thinking too much: introspection can reduce the quality of preferences and decisions. Journal of personality and social psychology, 60(2), 181.

46. Winer, E. H., \& Bloebaum, C. L. (2001). Visual design steering for optimization solution improvement. Structural and Multidisciplinary Optimization, 22(3), 219-229.

47. Wolf, D., Simpson, T. W., \& Zhang, X. L. (2009, January). A preliminary study of novice and expert users' decision-making procedures during visual trade space exploration. In ASME 2009 International Design Engineering Technical Conferences and Computers and Information in Engineering Conference, San Diego, California, USA, Paper No. DETC2009-87294, pp. 1361-1371.

48. Wolf, D., Hyland, J., Simpson, T. W., \& Zhang, X. L. (2011). The Importance of Training for Interactive Trade Space Exploration: A Study of Novice and Expert Users. Journal of Computing and Information Science in Engineering, 11(3), 031009.

49. Wu, J., \& Azarm, S. (2001). Metrics for quality assessment of a multiobjective design optimization solution set. Journal of Mechanical Design, 123(1), 18-25.

50. Yan, X., Qiao, M., Li, J., Simpson, T. W., Stump, G. M., \& Zhang, X. (2012, January). A WorkCentered Visual Analytics Model to Support Engineering Design with Interactive Visualization and Data-Mining. In System Science (HICSS), 2012 45th Hawaii International Conference on (pp. 18451854). IEEE.

51. Yan, X., Qiao, M., Simpson, T. W., Li, J., \& Zhang, X. L. (2011, January). LIVE: A Work-Centered Approach to Support Visual Analytics of Multi-Dimensional Engineering Design Data With Interactive 
Abi Akle A., Minel S., Yannau B. (2016) 'Infarmation Visualization For Selection In Design By Shopping', Research in Engineering Design, 28(I), pp. 99-117, doi: 10.1007/s00163-016-0235-2

Visualization and Data-Mining. In ASME 2011 International Design Engineering Technical Conferences and Computers and Information in Engineering Conference, Washington, DC, USA, Paper No. DETC2011-48333, pp. 825-834.

52. Yannou, B., \& Hamdi, A. (2004). Truss dimensioning with an uncertainty reduction paradigm. In $D S$ 32: Proceedings of DESIGN 2004, the 8th International Design Conference, Dubrovnik, Croatia.

53. Yannou, B., Moreno, F., Thevenot, H. J., \& Simpson, T. W. (2005, January). Faster generation of feasible design points. In ASME 2005 International Design Engineering Technical Conferences and Computers and Information in Engineering Conference, Long Beach, California, USA, Paper No. DETC2005-85449, pp. 355-363.

54. Yannou, B., Troussier, N., Chateauneuf, A., \& Boudaoud, N. (2009). Dimensioning a product in preliminary design through different exploration techniques. International Journal of Product Development, 9(1), 140-163.

55. Yannou, B., Yvars, P. A., Hoyle, C., \& Chen, W. (2013). Set-based design by simulation of usage scenario coverage. Journal of Engineering Design, 24(8), 575-603.

56. Zhang, X. L., Simpson, T. W., Frecker, M., \& Lesieutre, G. (2009, January). Supporting trade space exploration of multi-dimensional data with interactive multi-scale nested clustering and aggregation. In ASME 2009 International Design Engineering Technical Conferences and Computers and Information in Engineering Conference, San Diego, California, USA, Paper No. DETC2009-87045, pp. 1341-1353.

57. Zhang, X., Simpson, T., Frecker, M., \& Lesieutre, G. (2012). Supporting knowledge exploration and discovery in multi-dimensional data with interactive multiscale visualisation. Journal of Engineering Design, 23(1), 23-47. 